\title{
Review \\ Differentiating Nanomaghemite and Nanomagnetite and Discussing Their Importance in Arsenic and Lead Removal from Contaminated Effluents: A Critical Review
}

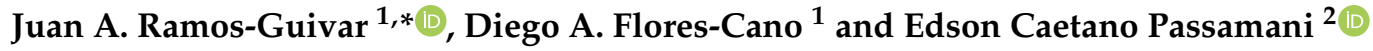 \\ 1 Grupo de Investigación de Nanotecnología Aplicada para Biorremediación Ambiental, Energía, Biomedicina \\ y Agricultura (NANOTECH), Facultad de Ciencias Físicas, Universidad Nacional Mayor de San Marcos, \\ Av. Venezuela Cdra 34 S/N, Ciudad Universitaria, Lima 15081, Perú; diego.flores4@unmsm.edu.pe \\ 2 Physics Department, Federal University of Espírito Santo, Vitória 29075-910, ES, Brazil; \\ passamaniec@yahoo.com.br \\ * Correspondence: juan.ramos5@unmsm.edu.pe; Tel.: +51-1-914728212
}

Citation: Ramos-Guivar, J.A.; Flores-Cano, D.A.; Caetano

Passamani, E. Differentiating Nanomaghemite and Nanomagnetite and Discussing Their Importance in Arsenic and Lead Removal from Contaminated Effluents: A Critical Review. Nanomaterials 2021, 11, 2310. https://doi.org/10.3390/nano11092310

Academic Editors: Michael Arkas, Ioannis Pashalidis, Dimitrios

A. Giannakoudakis,

Ioannis Anastopoulos and Christer Johansson

Received: 16 August 2021

Accepted: 30 August 2021

Published: 6 September 2021

Publisher's Note: MDPI stays neutral with regard to jurisdictional claims in published maps and institutional affiliations.

Copyright: (c) 2021 by the authors. Licensee MDPI, Basel, Switzerland. This article is an open access article distributed under the terms and conditions of the Creative Commons Attribution (CC BY) license (https:/ / creativecommons.org/licenses/by/ $4.0 /)$.

\begin{abstract}
Arsenic and lead heavy metals are polluting agents still present in water bodies, including surface (lake, river) and underground waters; consequently, the development of new adsorbents is necessary to uptake these metals with high efficiency, quick and clean removal procedures. Magnetic nanoparticles, prepared with iron-oxides, are excellent candidates to achieve this goal due to their ecofriendly features, high catalytic response, specific surface area, and pulling magnetic response that favors an easy removal. In particular, nanomagnetite and maghemite are often found as the core and primary materials regarding magnetic nanoadsorbents. However, these phases show interesting distinct physical properties (especially in their surface magnetic properties) but are not often studied regarding correlations between the surface properties and adsorption applications, for instance. Thus, in this review, we summarize the main characteristics of the co-precipitation and thermal decomposition methods used to prepare the nano-iron-oxides, being the co-precipitation method most promising for scaling up processes. We specifically highlight the main differences between both nanooxide species based on conventional techniques, such as X-ray diffraction, zero and in-field Mössbauer spectroscopy, X-ray photoelectron spectroscopy, X-ray absorption spectroscopy, and X-ray magnetic circular dichroism, the latter two techniques performed with synchrotron light. Therefore, we classify the most recent magnetic nanoadsorbents found in the literature for arsenic and lead removal, discussing in detail their advantages and limitations based on various physicochemical parameters, such as temperature, competitive and coexisting ion effects, i.e., considering the simultaneous adsorption removal (heavy metal-heavy metal competition and heavy metal-organic removal), initial concentration, magnetic adsorbent dose, adsorption mechanism based on $\mathrm{pH}$ and zeta potential, and real water adsorption experiments. We also discuss the regeneration/recycling properties, afteradsorption physicochemical properties, and the cost evaluation of these magnetic nanoadsorbents, which are important issues, but less discussed in the literature.
\end{abstract}

Keywords: nano- $\gamma-\mathrm{Fe}_{2} \mathrm{O}_{3}$; nano- $\mathrm{Fe}_{3} \mathrm{O}_{4}$; arsenic; lead; contaminated effluents; water purification

\section{Introduction}

Bulk magnetite $\left(\mathrm{Fe}_{3} \mathrm{O}_{4}\right)$ and maghemite $\left(\gamma-\mathrm{Fe}_{2} \mathrm{O}_{3}\right)$ are common iron-oxides (Fe-oxides) found in nature as minerals and in the corrosion industry [1,2]. However, with the appearance of nanotechnology and advances in new routes of synthesis (including physical, chemical, and biosynthesis), many researchers have tried to prepare either pure 'nanomagnetite' (nano- $\mathrm{Fe}_{3} \mathrm{O}_{4}$ ) or nanomaghemite (nano- $\gamma-\mathrm{Fe}_{2} \mathrm{O}_{3}$ ) or a mixture of these phases forming the core-shell-like nanosystems [3-10]. Moreover, it should be emphasized that these materials can exist in a ferrofluid form, magnetic nanopowders, solid magnetic matrices, core-shell-like structures, and magnetic colloid solutions. However, in a nanoscale 
regime, the results may suggest that it is hard to compare different nano- $\mathrm{Fe}_{3} \mathrm{O}_{4}$ or nano- $\gamma$ $\mathrm{Fe}_{2} \mathrm{O}_{3}$ when they are prepared from different routes. For instance, the three main issues found in nano-oxide systems are (i) the fast conversion from nano- $\mathrm{Fe}_{3} \mathrm{O}_{4}$ to nano- $\gamma-\mathrm{Fe}_{2} \mathrm{O}_{3}$, (ii) the different optical, thermal, magnetic, electronic, mechanical, textural, colloidal, surface, and adsorptive properties due to different Fe-oxide growth mechanisms [3-11], and (iii) the problem related to a critical size of the nanoparticles (NPs), i.e., below a certain critical radius $(\sim 10 \mathrm{~nm})$, these two Fe-oxide phases are rather difficult to differentiate even from the perspective of different conventional techniques, such as powder X-ray diffraction (pXRD), zero-field Mössbauer spectroscopy (MS), X-ray photoelectron spectroscopy (XPS), and Vibrating Sample Magnetometry (VSM) measurements, often yielding a bad interpretation and characterization of the correct Fe-oxide phase presented in the sample. According to the literature, many scientific works agree that this critical radius is located ca. $10 \mathrm{~nm}$ [3-11]. Below this critical size, nanoparticle (NP) surface magnetic effects are huge and considerable, giving rise to coexisted competitive magnetic effects. Unfortunately, most review reports have discussed Fe-oxide-based samples with sizes superior to this critical radius; hence, some interesting effects, such as superparamagnetism and superspinglass, are not fully studied. For example, da Costa et al. [12] reported an interesting review about $\gamma-\mathrm{Fe}_{2} \mathrm{O}_{3}$ and magnetite, but the studied particle sizes were bigger than $10 \mathrm{~nm}$; consequently, no superparamagnetic relaxation Mössbauer spectra were observed for temperatures below $300 \mathrm{~K}$. Another relevant review focus only on $\gamma-\mathrm{Fe}_{2} \mathrm{O}_{3} \mathrm{NPs}$ was conducted by Tuček et al. [13] more than a decade ago.

In particular, while Cornell et al. [1] summarized very well the distinct crystallographic and magnetic properties of $\mathrm{Fe}_{3} \mathrm{O}_{4}$ and $\gamma-\mathrm{Fe}_{2} \mathrm{O}_{3}$ at a bulk state, Greneche [14] devoted decades to the study of nano- $\gamma-\mathrm{Fe}_{2} \mathrm{O}_{3}$ and composites, including core-shell models. Regarding this issue, the present review has no intention to diminish previous findings and studies; instead, it invites the research community to have in mind the most important differences between both magnetic phases and, hence, their critical determination that is crucial in many applications.

Regarding the polluted agents commonly found in nature and concentrated by human activities, one has to mention the lead divalent, $\mathrm{Pb}$ (II), nonionic trivalent arsenic, As (III), and ionic pentavalent arsenic, $\mathrm{As}(\mathrm{V})$, which are inorganic species that are high contaminants found in surface and ground water liberated due to natural and human origins $[15,16]$. In particular, Bundschuh et al. [17] recently published the seven potential sources of arsenic (As) in Latin America that are currently exhibiting high concentrations of As in surface water, groundwater $\left(\mu \mathrm{g} \mathrm{L}^{-1}\right)$, and sediments $\left(\mathrm{mg} \mathrm{kg}^{-1}\right)$. The prevalence in water of both As species will depend on the $\mathrm{pH}$, ionic force, and redox potential [18]. In many countries, people drink and ingest water above the permissible levels given by the World Health Organization (WHO) [19], $10 \mu \mathrm{g} \mathrm{L}^{-1}$. Many strategies have been proposed to uptake this toxic metal from water, some of them including membrane separation, ion exchange, microbiological and photochemical oxidation, and adsorption [18,20]. Among the previous cleaning methods, the adsorption method seems to be the most promising due to its various amounts of new magnetic adsorbents that have been recently prepared [15]. These adsorbents can conjugate metal-oxide with commercial mesoporous materials (hybrids) to improve the adsorption capacity and efficiency at various laboratory conditions $[18,20]$. Moreover, the removal can be enhanced by conjugating the adsorbent with magnetic nanomaterials [21] and, hence, the strong pulling magnetic force of these materials makes them strong candidates to substantially reduce (i) the As pollution problem $[15,16]$ and (ii) the concentration of the adsorbent in remediated effluents. Binary and ternary magnetic nanocomposites $[21,22]$ are emerging nanohybrid materials with a high removal efficiency and can be obtained in high quantities by using the co-precipitation method, i.e., a technique that can be applied in the scaling up procedure and application at the industrial level. To the best of our knowledge, there has not been a review that deals specifically with the differences of $\mathrm{Fe}_{3} \mathrm{O}_{4}$ and $\gamma-\mathrm{Fe}_{2} \mathrm{O}_{3}$ NPs based on their magnetic surface configurations and their implications when prepared by co-precipitation and also discussing the simultaneous 
adsorption removal (heavy metal-heavy metal competition and heavy metal-organic removal) of $\mathrm{As}$ and $\mathrm{Pb}$ ions in contaminated effluents. Therefore, in this review, we bring recent magnetic hybrid nanoadsorbents (prepared essentially by the co-precipitation method) for $\mathrm{As}$ and $\mathrm{Pb}$ removal, focused on a multiparametric physicochemical analysis and cost evaluation.

\section{Synthesis Methods of Magnetic NPs}

\subsection{Co-Precipitation Method}

The co-precipitation method consists of a mixture of iron salts, including sulphates, ferric chloride $\left(\mathrm{FeCl}_{3}\right)$, iron (II) chloride $\left(\mathrm{FeCl}_{2}\right)$, or nitrates $\left(\mathrm{FeNO}_{3}\right)$ that precipitate in a high alkaline medium ( $\mathrm{pH}$ that varies between 10.0 and 12.0), as schematically displayed in Figure 1a. The pioneer in using the co-precipitation method was Massart, who, in 1981, prepared magnetic particles ( $12 \mathrm{~nm}$ in mean size) in an acid and a basic medium without the use of stabilizers [23]. Kinetic factors that influence the nucleation and growth of the ironoxide crystallites are the most important in the co-precipitation synthesis. The influence of bases in the nanoparticle growth mechanism, such as ammonium hydroxide $\left(\mathrm{NH}_{4} \mathrm{OH}\right)$, sodium hydroxide $(\mathrm{NaOH})$, and methylamine $\left(\mathrm{CH}_{3} \mathrm{NH}_{2}\right)$, were systematically studied by Jolivet in 2004 [24]. Roth et al. [6] also studied the influence of several physicochemical factors in the synthesis of iron-oxide NPs.

The major advantage from the co-precipitation method is the big quantities, in terms of mass, that can be produced, i.e., it is an important factor for technological and environmental purposes, and the major drawback is the size-controlled particle size distribution in a limited range from 3 to $20 \mathrm{~nm}$. However, this issue can be solved by adding either other inorganic or organic agents to easily control the size below $10 \mathrm{~nm}$. According to the literature, this particle size is three times below the magnetic critical diameter established by the formation of magnetic multi-domains for $\mathrm{Fe}_{3} \mathrm{O}_{4}$ and $\gamma-\mathrm{Fe}_{2} \mathrm{O}_{3}$ [25]. On the other hand, it should be pointed out that other methods (e.g., mechanical milling) can produce NPs with sizes about $13 \mathrm{~nm}$ (mean particle size) only after $90 \mathrm{~h}$ of milling [26], which may make this method inefficient for scale-up processes.

Some important additional details about the co-precipitation route are:

1. The solution of $\mathrm{FeCl}_{2} \cdot 4 \mathrm{H}_{2} \mathrm{O}$ has the complex $\mathrm{Fe}\left[\mathrm{H}_{2} \mathrm{O}\right]_{6}^{2+}$, which gives the solution a green-like color.

2. The process of co-precipitation is achieved by adding $\mathrm{NaOH}$ to the solution to achieve a high alkaline $\mathrm{pH}$, following the reaction:

$$
\mathrm{Fe}\left[\mathrm{H}_{2} \mathrm{O}\right]_{6}^{2+}+\mathrm{Fe}\left[\mathrm{H}_{2} \mathrm{O}\right]_{6}^{3+}+\mathrm{NaOH} \rightarrow \mathrm{Fe}(\mathrm{OH})_{2}+\mathrm{Fe}(\mathrm{OH})_{3} \rightarrow \mathrm{Fe}_{3} \mathrm{O}_{4} \downarrow
$$

This reaction is spontaneous, and the obtained precipitate is $\mathrm{Fe}(\mathrm{OH})_{2}$ salt, which is poorly soluble in water [27]. Jolivet et al. [28] proved that when the molar ratio $\mathrm{Fe}^{2+}: \mathrm{Fe}^{3+}$ is $1: 2$, the chemical reaction is almost immediate at room temperature (RT), being a small fraction of $\mathrm{Fe}^{2+}$ sufficient to crystallize all the Fe into an Fe spinel structure. On the other hand, Gokon et al. [29] confirmed that the reaction mechanism with a molar ratio of $\mathrm{Fe}^{2+}: \mathrm{Fe}^{3+}=1: 2$ is given by:

$$
\mathrm{Fe}(\mathrm{OH})_{2}+\mathrm{Fe}(\mathrm{OH})_{3} \rightarrow\left[\left(\mathrm{Fe}^{3+}\right)\left(\mathrm{Fe}^{2+}\right)_{2}\left(\mathrm{OH}^{-}\right)\left(\mathrm{O}^{2-}\right)_{2}\right]^{2-}+2 \mathrm{H}_{2} \mathrm{O} \rightarrow \mathrm{Fe}_{3} \mathrm{O}_{4} \downarrow+\mathrm{H}_{2} \mathrm{O}
$$

During the reaction, an unstable intermediate green color solution is obtained. In the case of $\mathrm{Fe}^{2+}: \mathrm{Fe}^{3+}=1: 2$, the intermediate product is $\mathrm{FeO}(\mathrm{OH})\left(\mathrm{s}-\mathrm{FeOH}{ }^{+}\right)$, which transforms into $\mathrm{Fe}_{3} \mathrm{O}_{4}$.

As suggested by Equations (1) and (2), the water consumption is an important fact to overcome in the co-precipitation method by underlying its use in the industry, especially in NP washing procedures that often require subsequent steps. It should also be noted that the Fe-oxide NPs, prepared by this method, may frequently present -OH groups at the particle surface that can be avoided using ethanol in the washing procedure. 
Regarding the magnetic properties obtained by the co-precipitation method, the NPs can be obtained in three forms: (i) magnetic nanocomposites, (ii) core-shell-like nanostructures, and (iii) magnetic solid matrices. As expected, interesting new magnetic effects, which are still a source of discussion in the scientific literature, appear in each of these configurations due to the predominance of magnetic surface effects.

In particular, novel magnetic properties were observed in ethylenediaminetetraacetic acid (EDTA) functionalized nano- $\gamma-\mathrm{Fe}_{2} \mathrm{O}_{3}$ prepared by co-precipitation [30]. Three coprecipitation routes were established to synthesize the materials with sizes no bigger than $10 \mathrm{~nm}$, but also no smaller than $4 \mathrm{~nm}$. Then, EDTA acted as a controlled-size reagent that also favors new surface magnetic configuration; consequently, favoring the existence of an exchange bias field that strongly depends on the EDTA shell thickness. In brief, it was experimentally proven that surface (or interface) tailoring by co-precipitation is suitable to observe other magnetic effects [30]. Another important magnetic property found in $\mathrm{Fe}-$ oxide NPs when these NPs are embedded in solid matrices (mesoporous and microporous adsorbents) is the superspinglass state not fully comprehended [31].

\subsection{Thermal Decomposition Method}

This method seems to be the most reliable at the time to synthesize pure stoichiometric $\mathrm{Fe}_{3} \mathrm{O}_{4}$ NPs with sizes below $10 \mathrm{~nm}$, a narrow particle size distribution (PSD) and with exotic particle geometries. Some researchers have demonstrated to tune the size and shape of $\mathrm{Fe}_{3} \mathrm{O}_{4}$ NPs by using several solvents with different boiling points [4,32]. The most common precursor is iron (III) acetylacetonate, $\mathrm{Fe}(\mathrm{acac})_{3}$, that is thermally decomposed in the presence of 1-octadecene and the surfactants oleic acid and oleylamine (controlling size reagents). The thermal decomposition method frequently requires several steps [33]: (i) temperatures (ca. $300^{\circ} \mathrm{C}$ ) higher than those used in the co-precipitation process (range of $60-80^{\circ} \mathrm{C}$ ), (ii) expensive organic precursors and solvents, (iii) long synthesis periods, (iv) careful laboratory conditions, and (v) a subsequent exchange transfer mechanism to obtain high hydrophilic Fe-oxide NPs. However, significant monodispersity can be achieved by the careful handling of the procedures, as described in Figure 1b-e. In addition, the possibility of tuning the morphological appearance of Fe-oxide NPs may also allow to handle and tune the magnetic properties (by controlling the magnetic shape anisotropy). For example, Sun et al. [4] made progress in controlling the exchange bias behavior in core-shell $\mathrm{FeO} / \mathrm{Fe}_{3} \mathrm{O}_{4}$ NPs. Their systems $(\sim 35 \mathrm{~nm})$ were synthesized by high temperature decomposition of $\mathrm{Fe}(\mathrm{acac})_{3}$ in the presence of oleic acid and oleylamine at $300{ }^{\circ} \mathrm{C}$. An exchange bias field of -226 (3) $\mathrm{mT}$ was obtained for this configuration.

\subsection{Bulk Effects in $\mathrm{Fe}_{3} \mathrm{O}_{4}$ and $\gamma-\mathrm{Fe}_{2} \mathrm{O}_{3}$}

An excellent reference to study the bulk and granular properties of magnetite is given by Gorski et al. [35]. A typical bulk stoichiometric magnetite is represented by the formula $\mathrm{Fe}_{3} \mathrm{O}_{4}$, whilst a non-stoichiometric is represented by $\mathrm{Fe}_{3-\delta} \mathrm{O}_{4}$, where $\delta$ is an indicator of an oxidation state. On the other hand, the $\gamma-\mathrm{Fe}_{2} \mathrm{O}_{3}$ phase, which can be considered as a consequence of $\mathrm{Fe}_{3-\delta} \mathrm{O}_{4}$, is one of the first materials most experimentally investigated at the nanometric scale, because it presents important physical phenomena, such as superparamagnetism and magnetic competing effects [36-39]. In addition, nano$\gamma-\mathrm{Fe}_{2} \mathrm{O}_{3}$ exhibits a ferrimagnetic order in the grain core due to the uncompensated spins of Fe ions that occupy the two sub-lattices of the spinel structure [40], i.e., it represents an uncompensation of ions in the unit cells, generating a high Curie temperature of ca. $950 \mathrm{~K}$ and a magnetization of approximately $26.5 \mu \mathrm{B}$ / unit cell or a net magnetic moment of $2.5 \mu \mathrm{B} /$ unit ( $2.5 \mu \mathrm{B} / \gamma-\mathrm{Fe}_{2} \mathrm{O}_{3}$, where $\mu_{\mathrm{B}}$ represents the Bohr magneton) [40].

Indeed, the magnetic and spinel structures consist of two sub-lattices corresponding to Fe located in the tetrahedral sites (A) and in the octahedral sites (B) [1]. Generally, the super-exchange magnetic interactions between the $\mathrm{A}$ and $\mathrm{B}$ sub-lattices are stronger than those that occur within an individual sub-lattice, such as the Fe spins in each sub-lattice which are ferromagnetically aligned, while also being antiparallelly coupled between the 
sub-lattices in the bulk-like state [40]. According to the preparation and purity of the macroscopic/mass $\gamma-\mathrm{Fe}_{2} \mathrm{O}_{3}$ (bulk), the saturation magnetization $\left(M_{S}\right)$ is $\left(74-80 \mathrm{emu} \mathrm{g}^{-1}\right)$ and the coercivity $\left(H_{c}\right)$ can be found in the interval between 50 and 800 Oe at RT. If one compares it with other Fe-oxide compounds, the $M_{S}$ of the $\gamma-\mathrm{Fe}_{2} \mathrm{O}_{3}$ phase turns out to be less than that of $\mathrm{Fe}_{3} \mathrm{O}_{4}\left(92 \mathrm{emu} \mathrm{g}^{-1}\right)$, but greater than that of $\alpha-\mathrm{Fe}_{2} \mathrm{O}_{3}\left(0.1-0.4 \mathrm{emu} \mathrm{g}^{-1}\right)$.

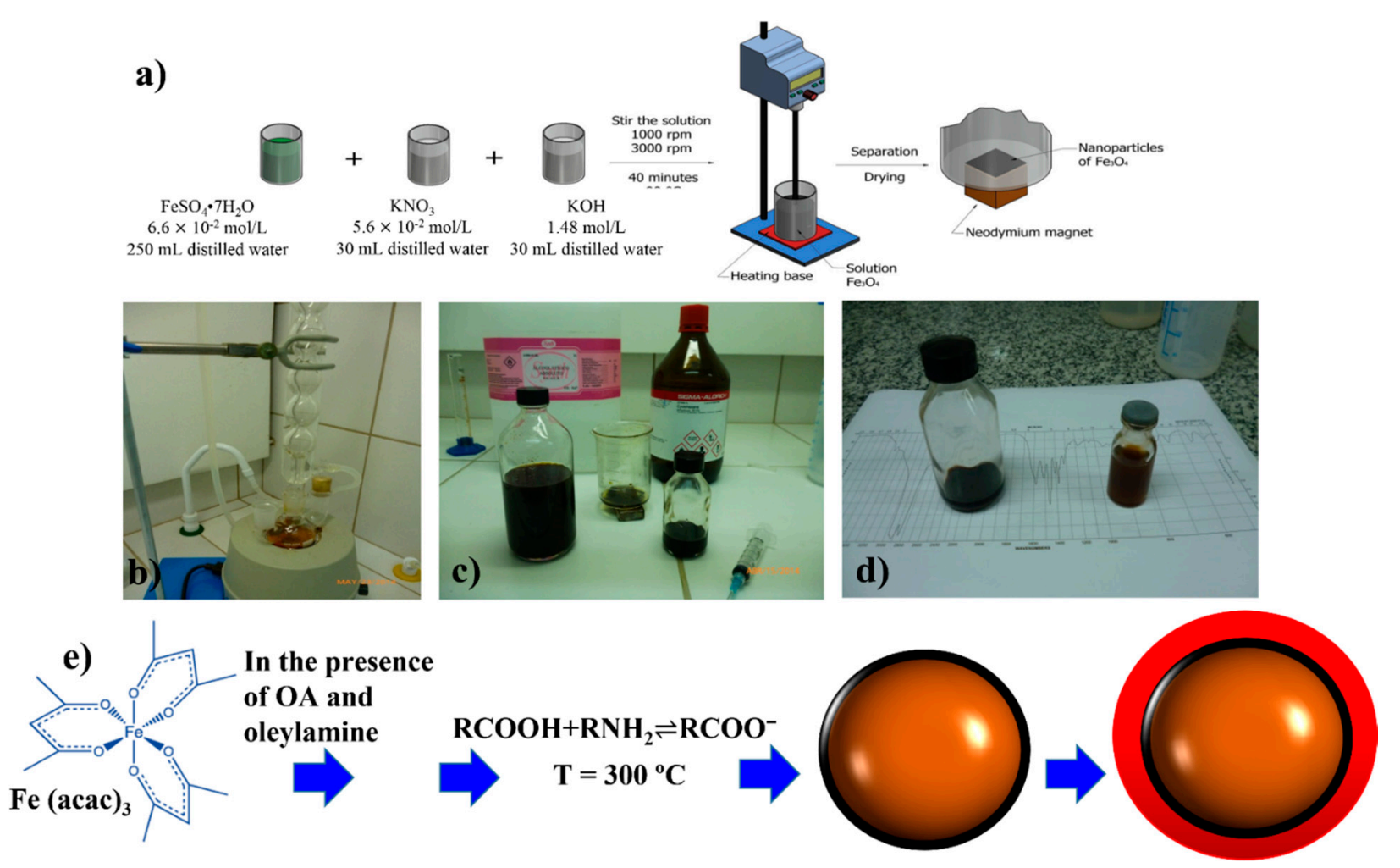

Figure 1. (a) Scheme for the co-precipitation method (reproduced with permission from Elsevier [34]). (b-d) Steps to synthesize $\mathrm{Fe}_{3} \mathrm{O}_{4}$ NPs by thermal decomposition method. (e) Biding model of surfactants to $\mathrm{Fe}_{3} \mathrm{O}_{4}$ core. Hydrophobic NPs in organic medium (black layer) and hydrophilic surface modification (red layer). $\mathrm{Fe}(\mathrm{acac})_{3}$ indicates the organic precursor of iron (III) acetylacetonate and OA is the oleic acid.

\section{Discussion about Main Differences Based on Physical Techniques}

\subsection{Can the XRD Technique Allow to Differentiate a Nanomagnetite or Nanomaghemite?}

It can be found through a simple search in the literature that the most applied technique to study structural properties and to characterize Fe-oxide NPs is still the conventional XRD method. However, is it possible to differentiate with conventional XRD experiments an $\mathrm{Fe}_{3} \mathrm{O}_{4}$ from a $\gamma-\mathrm{Fe}_{2} \mathrm{O}_{3}$ at a nanoscale regime? A careful analysis of data published in the literature led us to conclude that the answer, without a doubt, is negative. We can say that both inverse cubic spinel structures are similar, but not identical. The main reason is the presence of vacancies in the bulk $\gamma-\mathrm{Fe}_{2} \mathrm{O}_{3}$ structure, while the $\mathrm{Fe}_{3} \mathrm{O}_{4}$ phase has both tetrahedral sites fully occupied with $\mathrm{Fe}(\mathrm{III})$ spin states and octahedral sites fully completed with Fe(II) and Fe(III) spin states. Thus, the general formula to differentiate them is ${ }^{\mathrm{Tet}} \mathrm{Fe}^{3+}\left[{ }^{\mathrm{Oct}} \mathrm{Fe}_{1-3 \delta}^{2+} \mathrm{Fe}_{1+2 \delta}^{3+} \square_{\delta}\right] \mathrm{O}_{4}$, where $\square$ is related to the vacancies in the inverse cubic spinel structure [41-45]. Gorski et al. [35] analyzed the unit cell length (a) parameter for different nano- $\mathrm{Fe}_{3} \mathrm{O}_{4}$ as a function of the $\mathrm{Fe}(\mathrm{II}) / \mathrm{Fe}$ (III) ratio. As it can be observed in Figure 2, the lattice parameter of cubic conventional cell fluctuates between $a=8.33$ and $8.40 \AA$, where a total oxidized $\gamma-\mathrm{Fe}_{2} \mathrm{O}_{3}$ will depict a value of approximately $a=8.34 \AA$. It is important to highlight that the particle size reported in Gorski et al.'s work [35] was of $20 \mathrm{~nm}$, and the current sizes required for many nanotechnological applications must be below this value. More importantly, Fe-oxide NPs with smaller sizes will have uncompensated spins at the particle surface; consequently, a surface disorder layer occurs (often not 
detectable by conventional XRD experiments), leading to interesting magnetic properties due to finite-size effects. Therefore, Figure 2 summarizes and shows an intrinsic correlation between the lattice cubic parameter (a) values and crystalline grain sizes reported in the literature found in the spinel-like structures (the crystallite size values were obtained by the refinement of XRD data [42-44,46-50]). In a first approximation, it can be noticed that the values of lattice parameters for both Fe-oxide phases $\left(\mathrm{Fe}_{3} \mathrm{O}_{4}\right.$ and $\gamma$ - $\left.\mathrm{Fe}_{2} \mathrm{O}_{3}\right)$ are similar at the nanoscale, making the identification difficult. However, three different regions can be identified for all the Fe-oxide NPs: (i) the first (I) region, with sizes below $10 \mathrm{~nm}$, shows a variation of the parameter $a(\AA)$ values in the range of 8.34 to $8.43 \AA$, confirming the difficulty in differentiating between nano- $\mathrm{Fe}_{3} \mathrm{O}_{4}$ and nano- $\gamma-\mathrm{Fe}_{2} \mathrm{O}_{3}$; (ii) values of $a$ parameter between 8.35 and $8.39 \AA$ were obtained for grain sizes from 10 to $70 \mathrm{~nm}$ (region II); for the third (III) region, a constant value of $8.39 \AA$ was obtained, suggesting the predominance of the $\mathrm{Fe}_{3} \mathrm{O}_{4}$ atomic arrangement in high crystallite sizes. Moreover, a positive linear trend (red full line obtained from a fit) can be considered around for data in regions II and III, as suggested by Figure 2. Additionally, Schwaminger et al. [51] tried to differentiate between nano- $\mathrm{Fe}_{3} \mathrm{O}_{4}$ and nano- $\gamma-\mathrm{Fe}_{2} \mathrm{O}_{3}$ based on the analysis of the (440) Miller plane of an Fe-oxide sample prepared by co-precipitation. However, two problems can be pointed out: (i) no control in oxidation was conducted during the Fe-oxide NP's synthesis and (ii) the Scherrer method was used to estimate nanocrystallite diameters (using only one diffraction peak). The latter permits to mention that this integral breadth method is known to overestimate the real crystallite size, and the Rietveld method must be used for a better estimation. No other technique (e.g., Mössbauer spectroscopy) was discussed to prove the presence of pure nano- $\mathrm{Fe}_{3} \mathrm{O}_{4}$. On the other hand, González-Alonso et al. [52] recently studied the presence of $\mathrm{Fe}_{3} \mathrm{O}_{4}$ in an ensemble of $28 \mathrm{~nm}$ Fe-oxide NPs by means of neutron diffraction. The authors discussed the presence of nano- $\mathrm{Fe}_{3} \mathrm{O}_{4}$ for samples with mean sizes higher than $10 \mathrm{~nm}$, where significant clues (agglomeration) of nano- $\mathrm{Fe}_{3} \mathrm{O}_{4}$ are experimentally observed. From the structural point of view, it can be concluded that conventional XRD experiments can hardly bring any trustable information of the Fe-oxide phases (e.g., a $\mathrm{Fe}_{3} \mathrm{O}_{4}$ from a $\gamma-\mathrm{Fe}_{2} \mathrm{O}_{3}$ ) in a nanoscale regime, at least, for grain sizes smaller than $10 \mathrm{~nm}$ (region I of Figure 2).

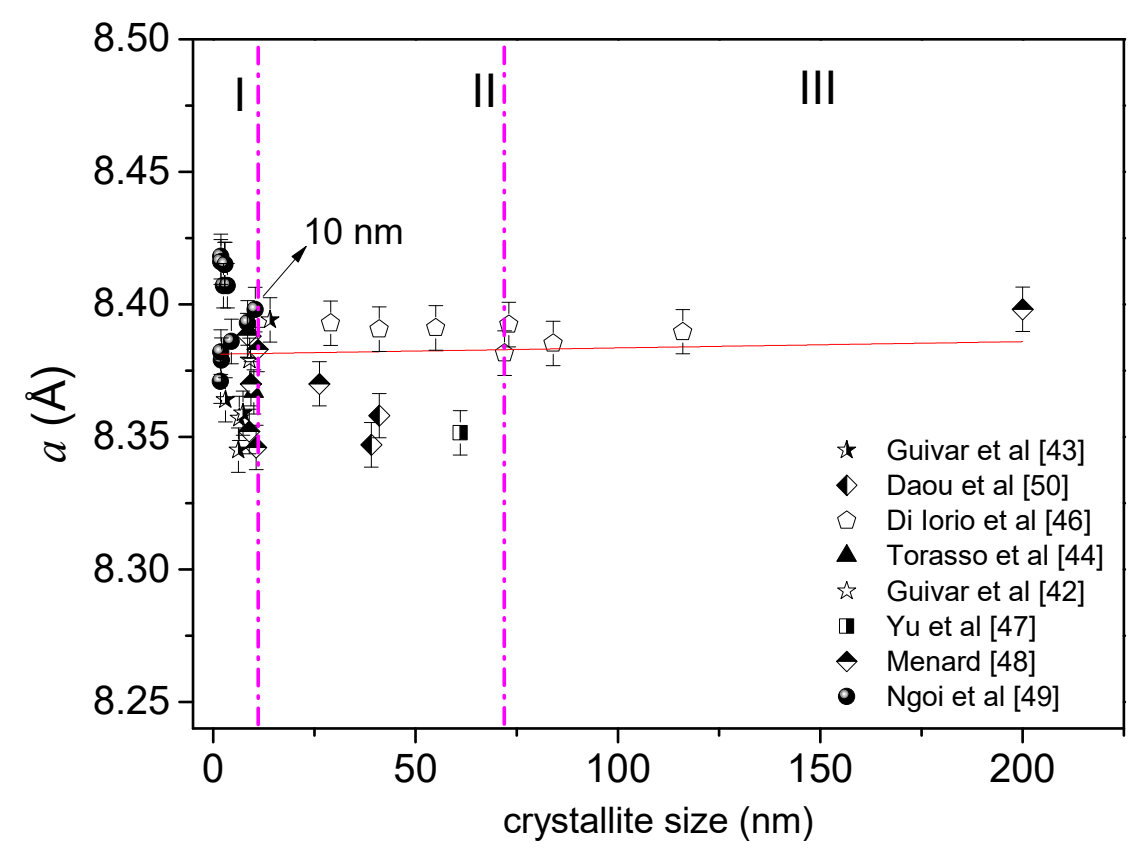

Figure 2. Lattice parameter $a(\AA)$ vs. crystallite size $(\mathrm{nm})$ for several Fe-oxide NPs prepared by co-precipitation. Figure developed by the authors. 


\subsection{Mössbauer Technique as the Main Tool of Differentiation}

Often, a bulk $\gamma-\mathrm{Fe}_{2} \mathrm{O}_{3}$ phase has been reported to have an asymmetric magnetic spectrum with narrow adsorption lines characteristic of two static magnetic components, represented, respectively, by site $\mathrm{A}(37.5 \%)$ and site $\mathrm{B}(62.5 \%)$ of the spinel-like structure [30]. For instance, Tuček et al. [13] reported the difference between bulk $\gamma-\mathrm{Fe}_{2} \mathrm{O}_{3}$ and nano- $\gamma$ $\mathrm{Fe}_{2} \mathrm{O}_{3}$ from the perspective of Mössbauer spectroscopy. The authors took the case of ideal superparamagnetic behavior as described by the ideal blocking temperature $\left(T_{B}\right)$ relation:

$$
T_{B}=\frac{K V}{k_{B} \ln \left(\frac{\tau_{m}}{\tau_{0}}\right)}
$$

where $K$ is the effective anisotropy constant, $k_{B}$ is the Boltzmann's constant, $V$ is the particle volume, $\tau_{m}$ is the characteristic time of the technique, and $\tau_{0}$ is the relaxation time constant. Equation (3) uses the case of monodisperse nano-ensembles with a narrow particle size distribution (PSD), anisotropic energy distributions and Fe-oxide NPs non-interacting magnetically. In the case of Fe-oxide NPs with a broad PSD, the Mössbauer analysis is more complex if one considers that the spectra will result in a combination of several components due to the spin relaxation and spin disorder surface effects. However, in general, the shape of Mössbauer spectra of magnetic NPs at $300 \mathrm{~K}$ can be used to classify the PSD in two different categories: (i) if the samples have a broad PSD, the Mössbauer spectra will have a mixture of relaxed superparamagnetic and magnetic components with broad adsorption lines. The Fe-oxide NPs responsible for this complex spectrum will have mean sizes of $10 \mathrm{~nm}$ or higher and the average blocking temperature $\left(T_{B}\right)$ will usually be above $300 \mathrm{~K}[12,41,53]$; (ii) if the Mössbauer spectrum at room temperature (RT) shows only a strong relaxed component (only a doublet or singlet corresponding to a superparamagnetic regime), a relatively narrow PSD can be assumed and, in addition, the interparticle magnetic interactions are either missing or weak. In the latter case, the samples must have Fe-oxide NPs with grain sizes smaller than $\sim 8 \mathrm{~nm}$ and the values of $T_{B}$, in general, will be below $300 \mathrm{~K}$ (the $T_{B}$ value will depend on the effective magnetic anisotropy constant and also the average volume of the particles) [50,54]. Furthermore, it should be mentioned that a nano- $\mathrm{Fe}_{3} \mathrm{O}_{4}$ also exhibits extra absorption lines with an inverted spectrum as compared to nano- $\gamma-\mathrm{Fe}_{2} \mathrm{O}_{3}$ [7]. These extra absorption lines at a low velocity are less intense and characteristic of a nano- $\mathrm{Fe}_{3} \mathrm{O}_{4}$ structure [7]; see Figure 3 (green sextet).

Taking results from the literature, it can be indirectly inferred that Mössbauer spectroscopy has often been implemented in Fe-oxide NPs with sizes bigger than $10 \mathrm{~nm}[8,11]$. As an example, da Costa et al. [12] studied the magnetic properties of nano- $\mathrm{Fe}_{3} \mathrm{O}_{4}$ and nano- $\gamma-\mathrm{Fe}_{2} \mathrm{O}_{3}$ prepared by wet chemical methods and, using integral low-energy electron Mössbauer spectroscopy (ILEEMS), they were able to differentiate between both nano-Feoxides with grain sizes of $15 \mathrm{~nm}$ (Fe-oxide NPs with sizes smaller than this value were not reported). Nedkov et al. [3] also studied the magnetic properties of nano- $\mathrm{Fe}_{3} \mathrm{O}_{4}$ synthesized by co-precipitation. Two samples with mean sizes of 10 (2) $\mathrm{nm}$ and 3 (2) nm were prepared and studied by ILEEMS. It was concluded that both nano- $\mathrm{Fe}_{3} \mathrm{O}_{4}$ samples had a contribution of $\gamma-\mathrm{Fe}_{2} \mathrm{O}_{3}$ on the sample surfaces. For samples with smaller particle sizes, a contribution of $30-40 \mathrm{vol} \%$ of the total $\mathrm{Fe}_{3} \mathrm{O}_{4}$ core was observed, but the authors did not show a $4.2 \mathrm{~K}$ Mössbauer spectrum to corroborate the presence of $\mathrm{Fe}_{3} \mathrm{O}_{4}$. A similar spectrum at RT was reported in [43] and it was attributed to a pure $\gamma-\mathrm{Fe}_{2} \mathrm{O}_{3}$ based on the resolved Mössbauer spectrum at $12 \mathrm{~K}$. Therefore, it is not possible to affirm from an RT Mössbauer spectrum that the sample is nano- $\mathrm{Fe}_{3} \mathrm{O}_{4}$ or nano- $\gamma-\mathrm{Fe}_{2} \mathrm{O}_{3}$, mainly because of the magnetic relaxation contribution, and also due to the fast oxidation of $\mathrm{Fe}(\mathrm{II})$ ions to $\mathrm{Fe}(\mathrm{III})$ at ambient conditions. Even in functionalized samples prepared by co-precipitation, a fast oxidation may also occur. Some examples are given in $[3,4,8,9,30,43,55-57]$ for inorganic and organic coatings. 


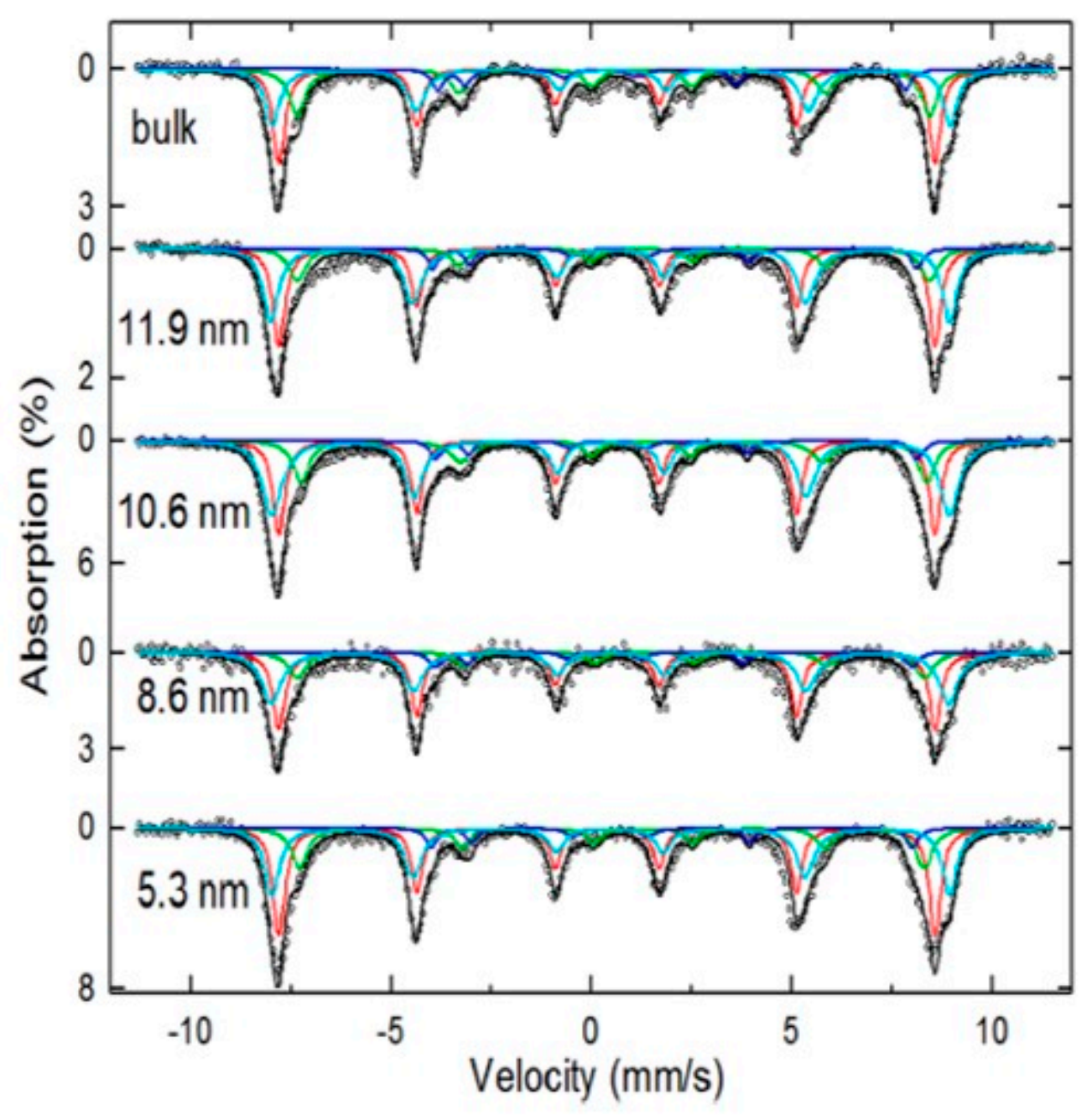

Figure 3. Mössbauer spectra of $\mathrm{Fe}_{3} \mathrm{O}_{4}$ at $6 \mathrm{~K}$ of bulk and $11.9 \mathrm{~nm}, 10.6 \mathrm{~nm}, 8.6 \mathrm{~nm}$, and $5.3 \mathrm{~nm}$ particles. Fitted spectra are (red) tetrahedral Fe(III), (light blue) octahedral Fe(III), (green and dark blue) octahedral Fe(II). (Reproduced with permission of Elsevier [7].)

As discussed above, either the XRD or zero-field ${ }^{57} \mathrm{Fe}$ Mossbauer spectroscopy will hardly differentiate the nano- $\mathrm{Fe}_{3} \mathrm{O}_{4}$ or nano- $\gamma-\mathrm{Fe}_{2} \mathrm{O}_{3}$ when the sizes are below $10 \mathrm{~nm}$ due to the Fe spin relaxation and spin surface disorder effects. To overpass this point, low temperatures, and in-field Mössbauer measurements are necessary. In other words, by applying an external magnetic field, the corresponding magnetic sites align to the external field direction, resolving the magnetic relaxation processes and the Fe atomic coordination and spin configurations. Thus, with this information, and assuming the different isomer shift $(\delta)$ values of these two Fe-oxide phases, one can more easily separate their contributions in samples for in-field Mössbauer experiments since it will allow to know the proportions of relative absorption areas for each magnetic site, as shown in Figure 4 and in Table 1 for samples of the pure nano- $\gamma-\mathrm{Fe}_{2} \mathrm{O}_{3}$-like phase that were EDTA functionalized. In addition, it was possible to demonstrate the fractions and the canting angles of Fe spins on the particle surfaces by performing in-field Mössbauer data, correlating, for example, with the thickness of the EDTA layer on the nano- $\gamma-\mathrm{Fe}_{2} \mathrm{O}_{3}$ NPs. Table 2 summarizes the main values for the hyperfine parameters of $\mathrm{Fe}_{3} \mathrm{O}_{4}$ and $\gamma-\mathrm{Fe}_{2} \mathrm{O}_{3}$ in both bulk and nanoscales. Therefore, to solve the problem associated with the nano- $-\mathrm{Fe}_{3} \mathrm{O}_{4}$ and nano- $\gamma-\mathrm{Fe}_{2} \mathrm{O}_{3}$ phases, Mössbauer experiments under high fields and low temperatures are required. 


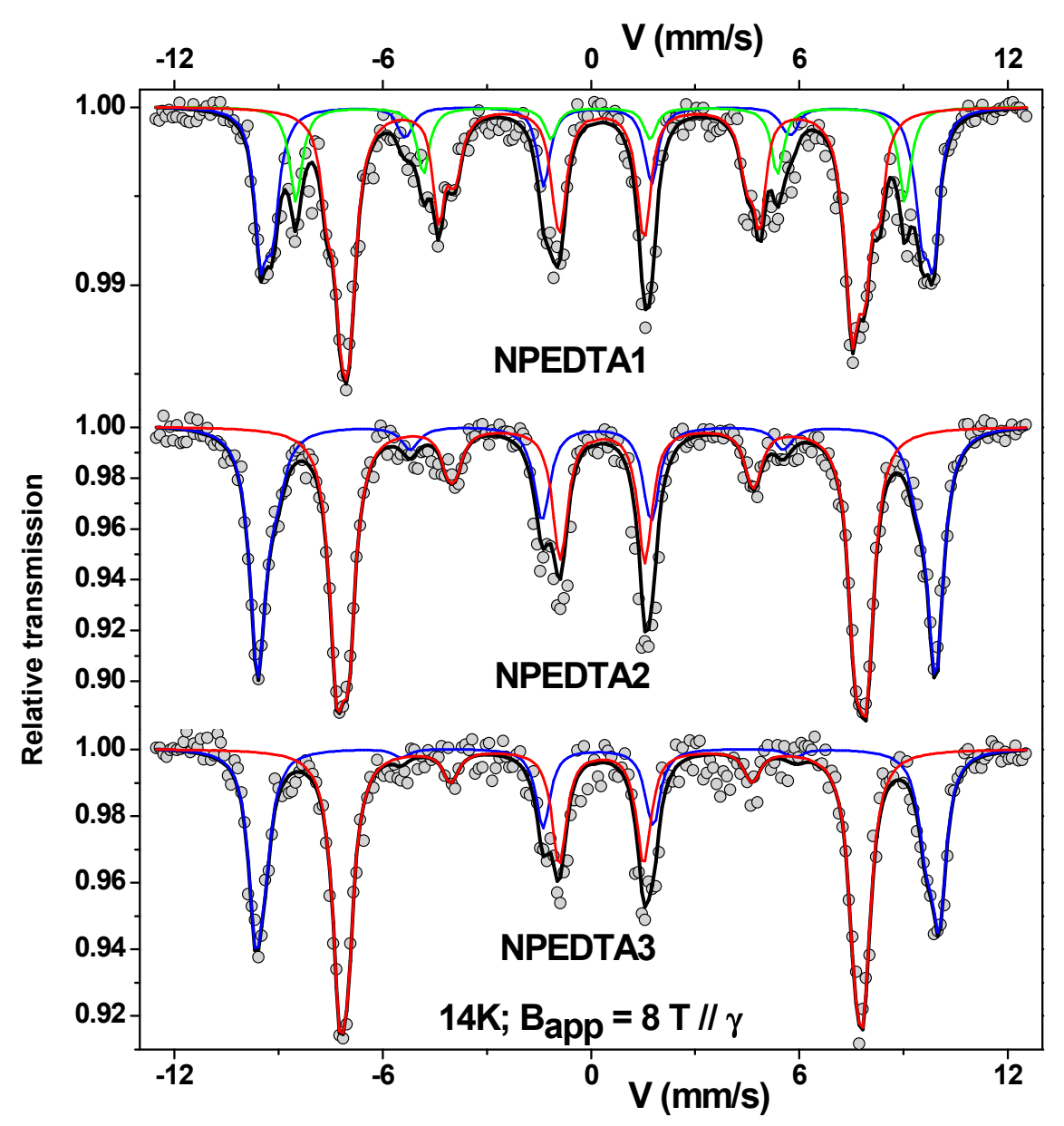

Figure 4. In-field Mössbauer spectra taken at $14 \mathrm{~K}$ in an applied field of $8 \mathrm{~T}$ for the ethylenediaminetetraacetic acid (EDTA) functionalized $\gamma-\mathrm{Fe}_{2} \mathrm{O}_{3}$ NPs (NPEDTA). Mössbauer spectra of the NPEDTA2 and NPEDTA3 were reproduced with permission of Elsevier [30]. 1, 2, and 3 indicates different routes of synthesis that can be checked in [30]. The lines red and blue represent the crystalline sites of $\gamma$-Fe2O3 NPs while the green line for NPEDTA1 sample is related to the surface magnetic contribution.

Table 1. Refined mean values of hyperfine parameters estimated from the in-field Mössbauer spectra recorded at $14 \mathrm{~K}$ under an $8 \mathrm{~T}$ external magnetic field applied parallel to the $\gamma$-ray beam for the NPEDTA1 $(4.0 \mathrm{~nm})$. In case of NPEDTA2 (7.6 nm) and NPEDTA3 $(7.0 \mathrm{~nm})$ samples were taken from [30]. A and B are related to the tetrahedral and octahedral sites of the $\gamma-\mathrm{Fe}_{2} \mathrm{O}_{3}$ phase. Notice that all hyperfine parameters here corresponded to a nano $\gamma-\mathrm{Fe}_{2} \mathrm{O}_{3}$ with a size smaller than $10 \mathrm{~nm}$. $\mathrm{F}$ $(\%)$ denotes the atomic proportions for site $\mathrm{A}$ and $\mathrm{B}$, respectively. $\mathrm{e}$ is the canted spin surface layer. $<\epsilon>$ is the quadrupolar shifting, $B_{\text {eff }}$ is the total effective field, and $<\mathrm{B}_{\mathrm{hf}}>$ is the mean hyperfine magnetic field.

\begin{tabular}{|c|c|c|c|c|c|c|c|c|}
\hline Sample & Site & $\begin{array}{c}<\delta>(\mathrm{mm} / \mathrm{s}) \\
\pm 0.02\end{array}$ & $\begin{array}{c}<2 \epsilon>(\mathrm{mm} / \mathrm{s}) \\
\pm 0.02\end{array}$ & $\begin{array}{c}<B_{\text {eff }}> \\
(\mathrm{T}) \\
\pm 0.5\end{array}$ & $\begin{array}{c}<\theta> \\
\left({ }^{\circ}\right) \\
\pm 5\end{array}$ & $\begin{array}{c}<\mathrm{B}_{\mathrm{hf}}> \\
(\mathrm{T}) \\
\pm 0.5\end{array}$ & $\begin{array}{c}\mathbf{F}(\%) \\
\pm 1\end{array}$ & $\begin{array}{c}\mathrm{e} \\
(\mathrm{nm}) \\
\pm 0.05\end{array}$ \\
\hline \multirow[t]{3}{*}{ NPEDTA1 } & $\mathrm{A}$ & 0.18 & -0.01 & 58.8 & 26 & 51.8 & 28 & 0.38 \\
\hline & B & 0.29 & 0.01 & 46.2 & 42 & 52.4 & 57 & 0.89 \\
\hline & $\mathrm{C}$ & 0.27 & -0.00 & 54.2 & 56 & 50.2 & 15 & 1.37 \\
\hline \multirow{2}{*}{ NPEDTA2 } & A & 0.36 & -0.00 & 59.6 & 21 & 52.2 & 43 & 0.24 \\
\hline & B & 0.52 & 0.02 & 46.2 & 28 & 53.3 & 57 & 0.42 \\
\hline \multirow{2}{*}{ NPEDTA3 } & A & 0.37 & -0.04 & 60.2 & 14 & 52.7 & 40 & 0.10 \\
\hline & B & 0.52 & 0.00 & 46.0 & 22 & 53.5 & 60 & 0.24 \\
\hline
\end{tabular}


Table 2. Hyperfine parameters obtained from Mössbauer technique for bulk and nano $\gamma-\mathrm{Fe}_{2} \mathrm{O}_{3} / \mathrm{Fe}_{3} \mathrm{O}_{4}$. RAA denotes the relative absorption area.

\begin{tabular}{lll}
\hline Bulk $\gamma-\mathrm{Fe}_{2} \mathrm{O}_{3}$ & $\mathrm{Nano}-\gamma-\mathrm{Fe}_{2} \mathrm{O}_{3}$ & $\mathrm{Bulk} \mathrm{Fe}_{3} \mathrm{O}_{4}$, nano- $^{-} \mathrm{Fe}_{3} \mathrm{O}_{4}$
\end{tabular}

At RT, the sextets collapse to a doublet or singlet-superparamagnetic-like regime (size $<10 \mathrm{~nm}$ ).

At $14 \mathrm{~K}$, it has perfect asymmetric sextets.

At $14 \mathrm{~K}$, the in-field Mössbauer measurements reveal two or three magnetic components depending on particle size. Broadenings can still be significant due to overbarrier fluctuations of smaller particles.

At RT, fluctuating hyperfine magnetic fields are presented.

Static hyperfine magnetic fields. At $14 \mathrm{~K}$, superparamagnetic relaxation is negligible and two defined sextets are observed.

At RT, the appearance of the complex shapes with mixed components that depend on the particle size, anisotropy energies, blocking temperature
Hyperfine magnetic fields at $14 \mathrm{~K}$ [30]:

$\mathrm{B}_{\mathrm{hf}, \mathrm{A}}=\mathbf{5 2 . 0 \mathrm { T }}$

$\mathrm{B}_{\mathrm{hf}, \mathrm{B}}=53.1 \mathrm{~T}$

distributions, and magnetic interactions are observed. At $14 \mathrm{~K}$, if sizes are smaller than $10 \mathrm{~nm}$, strong spin canting behavior occurs, and the hyperfine parameters slightly differ. For sizes bigger than 10 $\mathrm{nm}$, the hyperfine parameters are equal to the bulk expected ones.

For fittings an average $<\delta>$ for each site must be considered.

Isomer shifts at $14 \mathrm{~K}$ [30]:

$\delta_{\mathrm{A}}=0.36 \mathrm{~mm} / \mathrm{s}$

$\delta_{\mathrm{B}}=0.48 \mathrm{~mm} / \mathrm{s}$
Bulk stoichiometric $\mathrm{Fe}_{3} \mathrm{O}_{4}$ depicts two characteristic sextets at RT, while the nano- $\mathrm{Fe}_{3} \mathrm{O}_{4}$ presents a collapse spectrum to a doublet or singlet.

At $6 \mathrm{~K}$, the spectrum is fitted with three components of tetrahedral $\mathrm{Fe}^{3+}$, octahedral $\mathrm{Fe}^{3+}$, and octahedral $\mathrm{Fe}^{2+}[7]$.

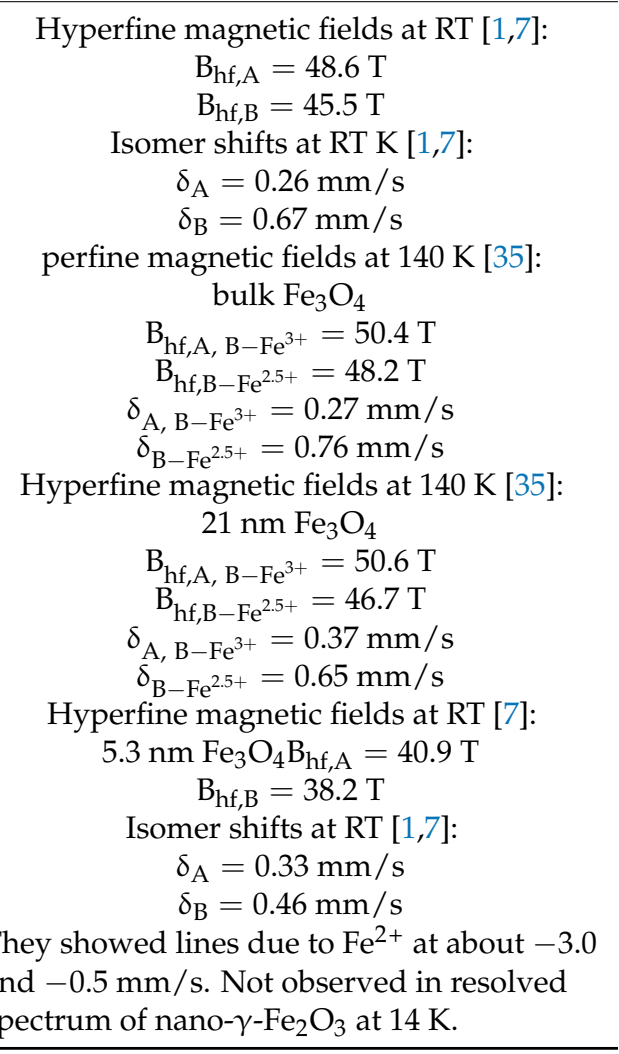

\subsection{High Resolution XPS and Synchrotron Radiation Techniques}

XPS has been employed for surface (few nanometers) characterization of functionalized Fe-oxide NPs. For example, Wilson et al. [55] investigated the stabilization of oleylamine/oleic acid-capped $\mathrm{Fe}_{3} \mathrm{O}_{4} \mathrm{NPs}$. The characteristic low energy peak at $710.2 \mathrm{eV}$ was employed to identify Fe(II), while the peak located at $710.8 \mathrm{eV}$ related to $\mathrm{Fe}^{3+}$ octahedral species, was observed. Despite the identification of both valence states, the $2 p_{3 / 2} / 2 p_{1 / 2}$ ratio was found equal to 1.7 , a value that is close to that found in the ideal stochiometric $\mathrm{Fe}_{3} \mathrm{O}_{4}$ (ratio of 2). To account this difference, the authors suggested an additional contribution of $\mathrm{Fe}^{3+}$ coming exclusively from the surface due to the presence of $\gamma-\mathrm{Fe}_{2} \mathrm{O}_{3} \mathrm{NPs}$. On the other hand, Lavorato et al. [8], using XPS measurements, studied the $12.1 \mathrm{~nm}^{\prime} \mathrm{Fe}_{3} \mathrm{O}_{4}{ }^{\prime}$ NPs coated with $\mathrm{Zn}_{0.6} \mathrm{Fe}_{2.4} \mathrm{O}_{4}$ for as-prepared and 6-month aged samples. They identified three Fe $2 p_{3 / 2}$ energy bands at 710.1,711.5, and 713.8 eV related, respectively, to Fe(II) and $\mathrm{Fe}(\mathrm{III})$ in the octahedral and $\mathrm{Fe}^{3+}$ in the tetrahedral sites. In addition, the ratio $\mathrm{Fe}(\mathrm{II}) / \mathrm{Fe}$ (III) was found to be equal to 0.39 for the as-prepared and 0.31 for the aged samples, suggesting a gradual oxidation of the particle surface. A similar oxidation behavior was observed by Bhattacharjee et al. [9], where a satellite peak at $718.08 \mathrm{eV}$ was assigned to the surface peak of the $\gamma-\mathrm{Fe}_{2} \mathrm{O}_{3}$ phase and related to partial oxidation of the Fe-oxide NP surface. On the 
other hand, the functionalization of $\gamma-\mathrm{Fe}_{2} \mathrm{O}_{3} \mathrm{NPs}$ with nanohydroxyapatite, as obtained by the co-precipitation technique, was investigated by Guivar et al. [41] and the XPS results showed the $\mathrm{Fe}_{2} \mathrm{p}_{3 / 2}$ at $710.7 \mathrm{eV}$ related to $\mathrm{Fe}(\mathrm{III})$ in a total oxidized $\gamma-\mathrm{Fe}_{2} \mathrm{O}_{3}$. However, as can be noticed from Guivar et al. [41]'s paper, the mathematical fit could also be conducted with three peaks assuming the presence of $\mathrm{Fe}_{3} \mathrm{O}_{4}$.

In the resume, this type of analysis obtained from broad lines, in principle, seems to have a strong mathematic character; consequently, the fit model should be carefully conducted and supported by other high-resolution techniques. Based on the above discussions, there is an important issue that still deserves to be stressed: when is the exact time that a transformation from nano- $\mathrm{Fe}_{3} \mathrm{O}_{4}$ to nano- $\gamma-\mathrm{Fe}_{2} \mathrm{O}_{3}$ occurs? According to results reported in the literature, the thermal decomposition method allows a better control of the surface oxidation process as compared to the co-precipitation method. Considering that the nanomaterials have a large active surface, the oxidation process will occur instantly, forming a core-shell-like nanosystem; therefore, it is hard to believe that fully stoichiometric nano- $\mathrm{Fe}_{3} \mathrm{O}_{4} \mathrm{NPs}$ can be prepared, as has been claimed in the literature several times $[3,8,9,55-57]$. One possibility to solve this point is to perform experiments in high resolution facilities, such as a synchrotron light to probe spin structures of different samples. As an example, high energy resolution techniques, such as X-ray absorption spectroscopy (XAS) and X-ray magnetic circular dichroism (XMCD) have also been applied to elucidate the magnetic properties of Fe-oxide core-shell nanosystems. Jiménez-Villacorta et al. [56] reported that Fe-oxide NPs composed of $70 \% \mathrm{Fe}_{3} \mathrm{O}_{4}$ and $30 \% \gamma-\mathrm{Fe}_{2} \mathrm{O}_{3}$ exhibited a magnetic signal at $1 \mathrm{kOe}$ and $25 \mathrm{~K}$, suggesting the formation of a core-shell system. Moreover, Bonanni et al. [57] studied the effect of a low-field (160 Oe) XMCD measurement on the magnetic properties of $13 \mathrm{~nm}$ and $7.0 \mathrm{~nm}$ hollow $\gamma-\mathrm{Fe}_{2} \mathrm{O}_{3} \mathrm{NPs}$ and $5.0 \mathrm{~nm}$ bare NPs. The XAS measurement of the $7.0 \mathrm{~nm} \gamma-\mathrm{Fe}_{2} \mathrm{O}_{3}$ displays the main peak of the $\mathrm{FeL}_{3}$ edge (site $\mathrm{A}$ ) and the double peak at the $\mathrm{FeL}_{2}$ edge (site B), i.e., the XCMD spectrum revealed information of site $\mathrm{A}$ (positive peak) and site $\mathrm{B}$ (two negative peaks) [57]. Additionally, the bare and $13 \mathrm{~nm} \gamma-\mathrm{Fe}_{2} \mathrm{O}_{3}$ NPs showed the same prevalence of $\mathrm{Fe}(\mathrm{III})$ spins, but a reduction in the magnetization was observed for the 7.0 hollow NPs and related to the formation of a frustrated magnetic state at the particle surface. Anyhow, XPS and XMCD can be applied to bring information about the Fe valence state and also some information about the magnetism of the Fe-oxide NPs, but these techniques must also be applied simultaneously with the in-field Mossbauer one. Therefore, to understand the adsorption process, we have to characterize the sample deeply and the atomic and spin configurations must be raised up. From now on, we can start to discuss individually the adsorption process of As and $\mathrm{Pb}$ using the Fe-oxide NPs based on published results. For that, we analyze different experimental conditions ( $\mathrm{pH}$, dose, temperature, etc.).

\section{In-Detail Discussion of the Adsorbent Properties}

\subsection{As Adsorption Experiments}

\subsubsection{Individual As Adsorptive Properties}

Considering water magnetic remediation processes, it is of great interest to know the correct surface configuration of the Fe-oxide NPs from the atomic arrangement and magnetic point of view as presented in Table S1 (see Supplementary Material). Indeed, many magnetic Fe-oxide NP composites have been tested as As adsorbents in recent years [58-88]. Their adsorbent properties and experimental conditions are exposed and a comparison of their removal efficiency and an analysis of the experimental condition effects $(\mathrm{pH}$, temperature, adsorbent dose, initial concentration, particle size and shape, surface area, and saturation magnetization, equilibrium time, kinetic and isothermal adsorption parameters) [58-88] on the As removal are of great importance and are summarized in detail in Table S1. The main results suggest that the temperature has been a decisive factor in the adsorption removal efficiency and more specifically, the adsorption capacity rose with the temperature in several cases $[69,72]$. However, there also are special cases where the adsorption capacity first increases with the temperature, but it decreases, subsequently [58], 
indicating that the effect of temperature influences on As removal for all adsorbents (shown in Table S1) has still not been solved. In brief, various adsorbents have shown different temperature dependences in their performance in agreement with results published by Siddiqui et al. [89]. However, room temperature has been chosen by many authors due to its commonness in nature and because this temperature usually exhibits a good removal performance, reducing the cost of the entire process. The effects of $\mathrm{pH}$ on $\mathrm{As}(\mathrm{V})$ adsorption have been mainly attributed to the protonation and deprotonation of the adsorbent's surface below and above the p.z.c., respectively $[42,60,62-64,66,70]$. This effect is due to the negative charge of $\mathrm{As}(\mathrm{V})$, which engages in an electrostatic interaction with the surface radicals of the adsorbents. Another relevant factor is the radical's variability with pH of the adsorbates and adsorbents, although it contributes more to As(III) removal than to As(V) removal due to the As(III) charge neutrality $[47,59,66]$. As reported by Das et al. [66], the number of surface hydroxyl groups increases with the $\mathrm{pH}$ augments and, therefore, contributes towards the enhancement of the As(III) removal at a higher $\mathrm{pH}$. In other words, the As species change when the $\mathrm{pH}$ increases and, thus, the number of hydroxyl groups increases, raising the As(III) adsorption effectiveness [59].

In a first phenomenological description of As adsorption processes, the Langmuir adsorption model is the most used one $[42,60,64,65,70,75]$, while the Freundlich adsorption model can be considered as the second most applied [63,68,71] for both As(III) and As(V). For these reasons, it can be indirectly inferred that the monolayer adsorption mechanism is used more often than the multilayer adsorption. However, it must be noticed that Nisticò et al. [73] and Yu et al. [47] obtained better Langmuir model $\mathrm{R}^{2}$ values for As(III) adsorption, whereas a better fitting with the Freundlich model for As(V) adsorption was reported by Nikić et al. [74] and Zeng et al. [76]. The above results suggest that multilayer adsorption is dominant in the case of $\mathrm{As}(\mathrm{V})$ ions as compared to As(III). In addition, the Sips isotherm adsorption model, which consists of Langmuir and Freundlich models, was successfully applied to fit the adsorption isotherms of $\mathrm{MBC}$ [59], $\mathrm{Fe}_{2} \mathrm{O}_{3}-\mathrm{ZrO}_{2} / \mathrm{BC}$ [68], and nano- $\gamma-\mathrm{Fe}_{2} \mathrm{O}_{3}-\mathrm{TiO}_{2}-\mathrm{GO}$ nanohybrids [42]. It should be stressed that the Sips model is often used when no maximum adsorption saturation is reached, and the nano-adsorbent can continue capturing the heavy metal at higher concentrations.

To give an example of the As adsorption process by Fe-oxide NPs, we bring the work of Siddiqui et al. [58] which found that at $35^{\circ} \mathrm{C}$ and $45^{\circ} \mathrm{C}$ the Freundlich model fitted the adsorption isotherms of the nano- $\gamma-\mathrm{Fe}_{2} \mathrm{O}_{3} @$ starch better than the Langmuir model, while for the non-functionalized nano- $\gamma-\mathrm{Fe}_{2} \mathrm{O}_{3}$ the opposite happened. These findings could indicate that starch functionalization and temperature raising may enhance multilayer adsorption. Another important parameter in the As removal process is its concentration in the synthetic effluent. Navarathna et al. [59] measured the As(III) removal percentage at a constant adsorbent dose $(50 \mathrm{mg})$ and concentrations of 5,10 , and $20 \mathrm{mg} \mathrm{L}^{-1}\left(25^{\circ} \mathrm{C}\right.$, $\mathrm{pH}=7.0$ ). Navarathna et al. [59] found that: (i) the As percentage reached its highest value at $20 \mathrm{mg} \mathrm{g}^{-1}$ and (ii) it increased from 5 to $10 \mathrm{mg} \mathrm{g}^{-1}$ due to the multilayer adsorption character that occurs on the nano- $\mathrm{Fe}_{3} \mathrm{O}_{4}$ surface. Raval et al. [63] also found that increasing the $\mathrm{As}(\mathrm{V})$ concentration from $10 \mu \mathrm{g} \mathrm{L}^{-1}$ to $150 \mu \mathrm{g} \mathrm{L}{ }^{-1}$ lowered the adsorbed As percentage due to the saturation of available adsorption sites in the bilayer-OA@FeO NPs adsorbent. Moreover, they also observed that the adsorption capacity increased due to the high driving force to transfer the mass of elevated concentrations of $\mathrm{As}(\mathrm{V})$ in the solution, as observed in the adsorption isotherms. Briefly, considering the As adsorption process, the adsorbents that exhibited the best performances and their maximum adsorption capacities in $\mathrm{mg} \mathrm{g}^{-1}$ according to the Langmuir adsorption model, presented for both As species, and compared to other systems [58-63,65,66,68-99], were FeOX-GO-80 with $147 \mathrm{mg} \mathrm{g}^{-1}$ (arsenite) and $113 \mathrm{mg} \mathrm{g}^{-1}$ (arsenate) [64], $\gamma-\mathrm{Fe}_{2} \mathrm{O}_{3} @ \mathrm{CTF}-1$ with $198 \mathrm{mg} \mathrm{g}^{-1}$ (arsenite) and $102.3 \mathrm{mg} \mathrm{g}^{-1}$ (arsenate) [67], and $\gamma-\mathrm{Fe}_{2} \mathrm{O}_{3}-\mathrm{TiO}_{2}-\mathrm{GO}$ with $110.4 \mathrm{mg} \mathrm{g}^{-1}$ (arsenite) and $127.2 \mathrm{mg} \mathrm{g}^{-1}$ (arsenate) [42]. 


\subsubsection{Effect of $\mathrm{pH}$ in the Independent Removal of $\mathrm{As}(\mathrm{III})$ and $\mathrm{As}(\mathrm{V})$}

$\mathrm{pH}$ is definitely another important factor in the adsorption As removal experiments. In the solution with a pH ranging from 3.0 to 9.0, the charge neutral $\mathrm{H}_{3} \mathrm{AsO}_{3}$ is the dominant species of $\mathrm{As}(\mathrm{III})$, whereas for $\mathrm{As}(\mathrm{V})$, the negatively charged $\mathrm{H}_{2} \mathrm{AsO}_{4}{ }^{-}$and $\mathrm{HAsO}_{4}{ }^{2-}$ are the most prevalent forms $[92,100]$. The shifting of the $\mathrm{pH}_{\text {p.z.c. }}$ value indicated specifically the $\mathrm{As}(\mathrm{V})$ adsorption rather than electrostatic interactions. Therefore, the formation of complexed/precipitated As species at the surface of the nano- $\mathrm{Fe}_{3} \mathrm{O}_{4}$ adsorbent is one of the main adsorption mechanisms [93,101,102]. The $p \mathrm{Ka}$ values of As acid are $p \mathrm{Ka}_{1} \approx 2.3$, $p \mathrm{Ka}_{2} \approx 7.0$, and $p \mathrm{Ka}_{3} \approx 11.5$, indicating that the molecular form mainly exists in a solution at a $\mathrm{pH}<2.0$, while the anionic species $\left(\mathrm{H}_{2} \mathrm{AsO}_{4}{ }^{-}\right.$or $\left.\mathrm{HAsO}_{4}{ }^{2-}\right)$ exists at a $\mathrm{pH}$ in the interval 2-10 [14]. At $\mathrm{pH}<\mathrm{pH}_{\text {p.z.c., }}$ the protonation of surface functional generates a positive charge, which contributes to the favorable bonding of negatively charged arsenate ions. Both surface states and As speciation play significant contributions to electrostatic interactions (attraction/repulsion) between surface/ions, causing the intensity of the As to flux towards the specific adsorption sites. The enhancement of electrostatic attractions is, thus, highly feasible for $\mathrm{As}(\mathrm{V})$ species, while it is of minor importance for the neutral form of arsenous acid [103]. The $\mathrm{pH}$ also affects the surface charge of the adsorbent NPs. The surface of the adsorbent is positively charged when the equilibrium $\mathrm{pH}$ is below $\mathrm{pH}_{\text {p.z.c. }}$ and, consequently, negatively charged when the equilibrium $\mathrm{pH}$ is above

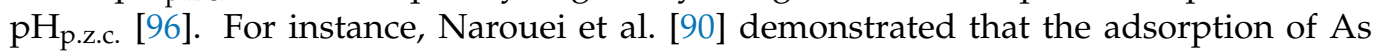
with $\mathrm{Fe}_{3} \mathrm{O}_{4} \mathrm{NPs}$ decreased by $30 \%$ when the experiments were carried out at a $\mathrm{pH}$ ca. 9; thus, the authors decided to perform most of the experiments in a $\mathrm{pH}$ of 7.5 that is a representative $\mathrm{pH}$ of most aquatic environments. In their research, humic acid (HA) has a greater structural complexity that makes it soluble at a high $\mathrm{pH}$ and insoluble in acidic conditions. The oxidation signals of $\mathrm{As}(\mathrm{III}) / \mathrm{As}(\mathrm{V})$ indicate that under these conditions ( $\mathrm{pH}$ 6-8 and 0-10 $\mathrm{mg} \mathrm{L}^{-1} \mathrm{HA}$ ), the As adsorbed in Fe-oxide NPs is predominantly present as $\mathrm{As}(\mathrm{III})$ and that any possible chemical oxidation by $\mathrm{Fe}_{3} \mathrm{O}_{4}$ would also imply the reduction from the newly formed As(V) back to As(III). Compared to the two mentioned cases, the reduction in $\mathrm{As}(\mathrm{V})$ to $\mathrm{As}(\mathrm{III})$ or probably the limitation of the initial oxidation of $\mathrm{As}(\mathrm{III})$ is more effective when HA is present. HA adsorption was found to increase the stability of NPs dispersions over a wide $\mathrm{pH}$ range and prevent salt-induced aggregation at a neutral $\mathrm{pH}$ [104]. Results from Paul et al. [91] agreed with the previous study when they investigated the influence of the $\mathrm{pH}$ dependence of $\mathrm{HA}$ on surface charges and found that in the absence of HA, which covers the surface charge of graphene oxide-Fe (GO$\mathrm{Fe}$ ), the p.z.c was $-34.8 \mathrm{mV}$ at $\mathrm{pH}$ 7.0. After coating with HA, the composite showed almost double the removal efficiency of $\mathrm{As}(\mathrm{III})$ and $\mathrm{As}(\mathrm{V})$ at a neutral $\mathrm{pH}$. To comprehend the positive role of HA towards As adsorption, Paul et al. [91] performed zeta potential measurements on all samples, which led them to envision the role of the $\mathrm{pH}$ and surface charge of $\mathrm{HA}$ dynamics with $\mathrm{GO}$ in the nano- $\mathrm{Fe}_{3} \mathrm{O}_{4}$ composite for As removal. Rashid et al. [92] also reported the adsorption of toxic inorganic As species from aqueous onto HA grafted $\mathrm{Fe}_{3} \mathrm{O}_{4}$ NPs (HA-MNP) in the $\mathrm{pH}$ range of the solution from 3.0 to 9.0. At a higher $\mathrm{pH}, \mathrm{As}(\mathrm{III})$ ions are more easily converted to $\mathrm{As}(\mathrm{V})$, which may be related to $p \mathrm{Ka}$, changes in speciation, and the susceptibility to oxidation. Despite electrostatic repulsions, chemical reactions between the functional groups of $\mathrm{HA}$ and $\mathrm{As}(\mathrm{V})$ appear to be dominant in the adsorption process. Yoon et al. [96], who investigated the adsorption of As(III) and $\mathrm{As}(\mathrm{V})$ on $\mathrm{Fe}_{3} \mathrm{O}_{4} /$ non-oxidative graphene (M-nOG) composites, reported that at a $\mathrm{pH}$ ranging from 4.0 to 10.0 , the As speciation is significantly modified. It should also be stated

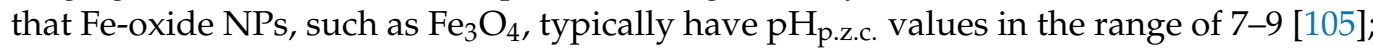
therefore, relevant for the As removal process. In Yoon et al.'s study [96], the $\mathrm{pH}_{\text {p.z.c }}$. value of M-nOG was determined to be $\mathrm{pH}$ 7.1. However, when the $\mathrm{pH}$ increased, the adsorption of $\mathrm{As}(\mathrm{V})$ on M-nGO decreased, because of the negatively charged surface sites on the adsorbent and increased competition between hydroxide ions $\left(\mathrm{OH}^{-}\right)$on $\mathrm{As}(\mathrm{V})$. With this interesting observation, Yoon et al. [96] indicated that the electrostatic interactions between 
the positively charged surface of M-nOG and anionic As $(\mathrm{V})$ species are one of the major factors for $\mathrm{As}(\mathrm{V})$ removal.

\subsubsection{As Adsorption Mechanism and Adsorption Isotherm Models}

In the research carried out by Rashid et al. [92], the results of removal showed that $\mathrm{As}(\mathrm{V})$ is adsorbed by HA-MNP faster and to a greater extent than $\mathrm{As}(\mathrm{III})$. A dose of HAMNP of $0.2 \mathrm{~g} \mathrm{~L}^{-1}$ and an initial concentration of $200 \mu \mathrm{g} \mathrm{L}-1$ of each species of As (As(III) and $\mathrm{As}(\mathrm{V}))$ were used. From these experiments, it was possible to reduce the level of As(III) below the drinking water maximum contaminant level of $10 \mu \mathrm{g} \mathrm{L}^{-1}$ in $180 \mathrm{~min}$, while only $60 \mathrm{~min}$ are required to decrease the $\mathrm{As}(\mathrm{V})$ concentration below the maximum contaminant level. Within one min of exposure to HA-MNP, the initial concentrations of $\mathrm{As}(\mathrm{III})$ and $\mathrm{As}(\mathrm{V})$ reduced by more than $50 \%$. So, this study indicates that the adsorption of $\mathrm{As}(\mathrm{III})$ and $\mathrm{As}(\mathrm{V})$ occurs in three different stages within the functionality of the HA coating via surface association, intraparticle diffusion, and complexation reactions or ligand exchange [92]. The initial As concentration was varied from 0.1 to $10 \mathrm{mg} \mathrm{L}^{-1}$ at a constant loading of HA-MNP $\left(0.2 \mathrm{~g} \mathrm{~L}^{-1}\right)$ and the adsorption process was found more consistent with the Freundlich model, indicating that the adsorption occurred in a multilayer formation and/or heterogeneous adsorption surface sites of the HA-MNP. From the Freundlich model, the value of $1 / \mathrm{n}$ less than one was an indicative of chemisorption of $\mathrm{As}(\mathrm{III})$ and $\mathrm{As}(\mathrm{V})$ on HA-MNP. Taleb et al. [93] used adsorbents containing cellulose support (MC) versus nanocellulose (NC) for the preparation of nano- $\mathrm{Fe}_{3} \mathrm{O}_{4}$ (referred as $\mathrm{MG}$ in [93]) and studied the As removal. The results indicated that the most acceptable fitting model should be conducted using the Langmuir and Freundlich isotherm models. Somewhat, the capacity of the As(III) removal of 68.2 and $17.8 \mathrm{mg} \mathrm{g}^{-1}$ was obtained with NCMA/L-MG and MC-O/L-MG, respectively. On the other hand, Lung et al. [95] found that the isotherms of the Langmuir and Freundlich models were the most suitable to describe the adsorption process of $\mathrm{Pb}(\mathrm{II}), \mathrm{Cd}(\mathrm{II})$, and $\mathrm{As}(\mathrm{III})$ on green $\mathrm{Fe}_{3} \mathrm{O}_{4} \mathrm{NPs}$. The adsorption energy (bT) was positive for all metal ions in the liquid matrix, indicating that the adsorption is an exothermic process [95]. In the study conducted by Yoon et al. [96], who studied the As(III) and $\mathrm{As}(\mathrm{V})$ removal using M-nOG composites, they found that the Sips isotherm model fit better the experimental data in comparison to the Langmuir and Freundlich models. This means that the As adsorption mechanism of the M-nOG hybrid is adequate for the combined Langmuir-Freundlich isotherm. In another research [97], the As(V) removal presented in the drinking water level was removed by using sand coated with nano- $\mathrm{Fe}_{3} \mathrm{O}_{4}$. The batch experiments were carried out in the presence of coexisting cations ( $\mathrm{Zn}(\mathrm{II}), \mathrm{Cd}(\mathrm{II})$, $\mathrm{Pb}(\mathrm{II}), \mathrm{Ni}(\mathrm{II}), \mathrm{Mg}(\mathrm{II}), \mathrm{Cr}(\mathrm{III})$, and $\mathrm{Fe}(\mathrm{III}))$ to understand its impact on the removal efficiency of $\mathrm{As}(\mathrm{V})$. The As adsorption data were fitted using the Langmuir and Freundlich models, obtaining an $\mathrm{R}^{2}$ value of 0.99 (1) for both models. Similar to the previous works [96,97], the adsorption of $\mathrm{As}(\mathrm{V})$ with nano- $\gamma-\mathrm{Fe}_{2} \mathrm{O}_{3}$ and graphene oxide $(\mathrm{GO})$ embedded in the polyacrylonitrile (PAN) polymer nanofibers matrix was also studied [98] on the basis of the Langmuir and Freundlich isotherm models. According to the Freundlich isotherm model, the maximum adsorption capacity was $36.1 \mathrm{mg} \mathrm{g}^{-1}$. An important point to be highlighted related to As removal is the fact that the adsorption efficiency was not affected by the presence of $\mathrm{Cl}^{-}, \mathrm{NO}_{3}{ }^{-}$, and $\mathrm{SO}_{4}{ }^{2-}$ ions, but with $\mathrm{PO}_{4}{ }^{3-}$ ions that reduced significantly the efficiency of adsorption [98].

\subsubsection{Effect of Organic Pollutants on the As Simultaneous Uptake}

The organic matter present in natural water ecosystems, as humic substances (HS), are between 0.1 and $20 \mathrm{mg} \mathrm{L}^{-1}$ [90]. They are produced from the decomposition of soil humus and various aquatic plants through various biological and chemical processes. HA is the main constituent and shows the most hydrophobic and high molecular weight fraction. It exhibits high sorption and complexation characteristics compared to other HS fractions [92] and can severely affect the As removal process when Fe-oxide NPs are applied [91,92]. Therefore, when As and HA are present in contaminated water, competitive adsorptions 
on Fe-oxide NPs can occur, reducing the adsorption of As. For $5 \mathrm{mg} \mathrm{L}^{-1} \mathrm{HA}$, Narouei et al. [90] reported a $97 \%$ removal efficiency of a $10 \mu \mathrm{M}$ solution of As, as can be seen in Table S2. However, when HA was prepared at $50 \mathrm{mg} \mathrm{L}^{-1}$, the removal efficiency of $10 \mu \mathrm{M} \mathrm{As}$ (III) decreased to $90.1 \%$, whereby As(III) has a lower accessibility to the surface of $\mathrm{Fe}_{3} \mathrm{O}_{4}$ NPs. Additionally, as expected, when the As concentration was $100 \mathrm{M}$, the As removal efficiency decreased for both HA levels. Paul et al. [91] indicated that the HA coating was influenced by graphene in the nano- $\mathrm{Fe}_{3} \mathrm{O}_{4}$ composite, which turned out to be an enhancing effect in the removal of As from contaminated effluents. After coating with $\mathrm{HA}$, the nano- $\mathrm{Fe}_{3} \mathrm{O}_{4}$ composite showed almost double the removal efficiency of $\mathrm{As}$ (III) and $\mathrm{As}(\mathrm{III})$ at a neutral $\mathrm{pH}$.

\subsubsection{Effect of the Coexisting Anions $\mathrm{Cl}^{-}, \mathrm{NO}_{3}{ }^{-}$, and $\mathrm{SO}_{4}{ }^{2-}$ on the As Adsorption}

In natural water sources, such as groundwater, several anions can coexist in As, and due to its competitive binding activity, it significantly decreases the percentage of As removal by applying Fe-oxide NPs [96,98]. Tripathy et al. [98] studied the effect of chloride $\left(\mathrm{Cl}^{-}\right)$, nitrate $\left(\mathrm{NO}_{3}{ }^{-}\right)$, sulphate $\left(\mathrm{SO}_{4}{ }^{2-}\right)$ on the adsorption of $\mathrm{As}(\mathrm{V})$ by PAN/GO/- $\mathrm{Fe}_{2} \mathrm{O}_{3}$ nanofibers, showing that these anions have no appreciable effect on $\mathrm{As}(\mathrm{V})$ adsorption [98], a result that agrees with the findings of Rashid et al. [92], Yoon et al. [96] and Taleb et al. [93]. On the other hand, there was no inhibition of As(III) adsorption [92,96] even when the adsorption of metal ions ( $\mathrm{As}(\mathrm{III}), \mathrm{Pb}(\mathrm{II})$, and $\mathrm{Cd}(\mathrm{II})$ ) from natural waters was performed. Therefore, $\mathrm{As}(\mathrm{III})$ has been retained very well on $\mathrm{Fe}_{3} \mathrm{O}_{4} \mathrm{NPs}$, while the other two metal ions, $\mathrm{Pb}$ (II) and $\mathrm{Cd}(\mathrm{II})$, were kept in a very small percentage due to the presence of competing metal ions that influence the sorption process [95]. The $\mathrm{Cl}^{-}$and $\mathrm{NO}^{3-}$ ions are only adsorbed as diffuse ions on the outer surfaces of the adsorbent [96], even when the As removal is increased due to the binding of negatively charged As species. Therefore, the concentration of negative charge increases in an electric double layer, and the enhancement of the ionic strength of the solution and the higher the concentration of counter cations could compensate the negative charges on the Fe-oxide hybrid surfaces. The observed facts, associated with the increase in ionic strength, lead to a higher adsorption of arsenate, indicating that the main adsorption mechanism is the formation of innersphere complexes [93]. On the other hand, sulfate, as divalent ions, forms external sphere complexes with strong electrostatic interactions, resulting in a higher ionic competition during the adsorption process. Finally, the effect of $\mathrm{SO}_{4}{ }^{2-}$ on As adsorption was relatively high for both $\mathrm{As}(\mathrm{V})$ [93], as well as for $\mathrm{As}(\mathrm{III})$ and $\mathrm{As}(\mathrm{V})$ [96].

\subsubsection{Influence of $\mathrm{PO}_{4}{ }^{3-}$ on the As Adsorption}

As-contaminated water containing phosphate anions as co-anions significantly decreased As removal [96-99]. The major adverse effect shown was the role of the phosphate competitive adsorption of $\mathrm{As}(\mathrm{V})$ compared to the coexisting $\mathrm{Cl}^{-}, \mathrm{NO}_{3}{ }^{-}$, and $\mathrm{SO}_{4}{ }^{2-}$ anions [93]. Rashid et al. [92] and Yoon et al. [96] demonstrated that the phosphate competition for HA-MNP and M-nOG active sites, respectively, decreases the adsorption for both As(III) and $\mathrm{As}(\mathrm{V})$, although $\mathrm{As}(\mathrm{III})$ was slightly more affected. These phenomena may be caused by the fact that phosphorus (P) and As have structural and chemical similarities, as they are both present in the same group 15 (5A) of the periodic table $[93,98]$. Therefore, they can form inner-sphere complexes through a ligand substitution reaction on the Fe-oxide hybrid surface [96] and, thus, exhibit adsorption and chelation properties similar to As and compete for adsorption on adsorbent sites [92]. Nevertheless, in rivers and groundwaters, the mass ratio between phosphate and As is usually very low, so there would be no major problems [92], as confirmed by an investigation performed by Lung et al. [95] who carried out the removal of $\mathrm{As}(\mathrm{III}), \mathrm{Pb}$ (II), and $\mathrm{Cd}$ (II) in a river sample using nano- $\mathrm{Fe}_{3} \mathrm{O}_{4}$ in the presence of anions and cations with a low concentration of $\mathrm{PO}_{4}{ }^{2-}$. The authors found that the removal of $\mathrm{As}$ (III) was optimal, whilst the removal of $\mathrm{Cd}(\mathrm{II})$ and $\mathrm{Pb}(\mathrm{II})$ was in a very small percentage. This observation may indirectly favor saying that the presence of metal ions competes in the sorption process at all. 


\subsubsection{Effect of the Coexisting of Metal Ions on the As Removal}

As mentioned above, As and metal ions often coexist in an ambient environment of the water system [92]. At $\mathrm{pH}=2.3-6.9$, the dominant $\mathrm{As}(\mathrm{V})$ species is $\mathrm{H}_{2} \mathrm{AsO}_{4}{ }^{-}[97,105]$. Darezereshki et al. [94] studied the influence of $\mathrm{Cu}(\mathrm{II}), \mathrm{Zn}(\mathrm{II})$, and $\mathrm{Mn}(\mathrm{II})$ ions on arsenate adsorption for $\mathrm{pH}<6$, with the highest adsorption rate of $\mathrm{As}(\mathrm{V})$ on copper $(\mathrm{Cu})$, zinc $(\mathrm{Zn})$, and manganese $(\mathrm{Mn})$; this was caused because As has a higher electronegativity value compared to $\mathrm{Cu}, \mathrm{Zn}$, and $\mathrm{Mn}$, being 2.2, 1.8, and 1.6, respectively. Additionally, the $\mathrm{H}_{2} \mathrm{AsO}_{4}{ }^{-}$species has a low charge density and low hydration capacity, so it can be easily adsorbed on nano- $\mathrm{Fe}_{3} \mathrm{O}_{4}$ due to its high mobility. On the other hand, $\mathrm{Cu}$ divalent ions have a better interaction with the negative charge of the adsorbent surface due to its hydrated ionic radius, which is smaller than zinc and manganese ions, being $4.19 \AA, 4.30 \AA$, and $4.43 \AA$ for $\mathrm{Cu}, \mathrm{Zn}$, and $\mathrm{Mn}$, respectively. Thus, the order of adsorption of these metals can be assumed as: $\mathrm{As}(\mathrm{V})>\mathrm{Cu}(\mathrm{II})>\mathrm{Zn}(\mathrm{II})>\mathrm{Mn}(\mathrm{II})$, even if the presence of cations in the solution can reduce the negative charge of the adsorbent surface and, therefore, facilitate the adsorption of the anionic arsenate. This effect is because the negative surface charge of the adsorbent attracts positive complexes such as copper $\left(\mathrm{CuH}_{2} \mathrm{AsO}_{4}{ }^{+}\right)$, manganese $\left(\mathrm{MnH}_{2} \mathrm{AsO}_{4}{ }^{+}\right)$, and zinc $\left(\mathrm{Zn} \mathrm{H}_{2} \mathrm{AsO}_{4}{ }^{+}\right)$ionic compounds that can electrostatically adsorb on the negative surface of the adsorbent. Kango et al. [97] investigated the effect of individual cations ( $\mathrm{Zn}(\mathrm{II}), \mathrm{Cd}(\mathrm{II}), \mathrm{Pb}(\mathrm{II}), \mathrm{Ni}(\mathrm{II}), \mathrm{Mg}(\mathrm{II}), \mathrm{Cr}(\mathrm{III})$, and $\mathrm{Fe}(\mathrm{III})$ ) on the adsorption of $\mathrm{As}(\mathrm{V})$ with nano- $\mathrm{Fe}_{3} \mathrm{O}_{4}$-coated sand. For the presence of cations with a concentration of $100 \mathrm{mg}$ $\mathrm{L}^{-1}$ coexisting in $\mathrm{As}(\mathrm{V})$, it showed a little interference with $\mathrm{As}(\mathrm{V})$ removal being between $94 \%$ and $99 \%$. In particular, the effect of cations on $\mathrm{As}(\mathrm{V})$ adsorption efficiency was found to be in the order of $\mathrm{Cr}(\mathrm{III})>\mathrm{Mg}$ (II) $>\mathrm{Ni}$ (II) $>\mathrm{Pb}$ (II) $>\mathrm{Cd}$ (II) $>\mathrm{Zn}$ (II) $>\mathrm{Fe}$ (III). The removal of As(III) was also not affected by the presence of inorganic ions in the adsorption with nano- $\mathrm{Fe}_{3} \mathrm{O}_{4}$, even in the presence of other heavy metal ions, as $\mathrm{Pb}(\mathrm{II})$ and $\mathrm{Cd}$ (II), which were retained in a very small percentage [6].

Darezereshki et al. [94] demonstrated the substitution effects of metal ions ( $\mathrm{Al}(\mathrm{III})$ and $\mathrm{Fe}(\mathrm{III})$ ) on arsenate adsorption at $\mathrm{pH}=2.0$, by the formation of $\mathrm{FeH}_{2} \mathrm{AsO}_{4}{ }^{2+}$ and $\mathrm{AlH}_{2} \mathrm{AsO}_{4}{ }^{2+}$ complexes with free $\mathrm{H}_{2} \mathrm{AsO}_{4}{ }^{-}$species. They showed that the $\mathrm{As}(\mathrm{V})$ removal capacity with nano- $\mathrm{Fe}_{3} \mathrm{O}_{4}$ decreased as the presence of $\mathrm{Al}$ and $\mathrm{Fe}$ ionic species increased with respect to arsenate. In addition, the presence of $\mathrm{Fe}$ (III) ions decreased arsenate adsorption more compared to the $\mathrm{Al}(\mathrm{III})$ ions. This observation was explained assuming the higher reactivity of $\mathrm{Fe}(\mathrm{III})$ and arsenate species $\left(\mathrm{H}_{2} \mathrm{AsO}_{4}{ }^{-}\right)$, and the higher stability of $\mathrm{FeH}_{2} \mathrm{AsO}_{4}{ }^{2+}$. However, the low concentration of Fe(III) ions in the solution did not seem to greatly affect As adsorption [94], which was confirmed by Rashid et al. [92], who performed the adsorption of As species (As(III) and As(V)) on the HA-MNP surface, having little interference from iron in the competition for the NP binding sites. These results demonstrated that As species can be efficiently removed using functionalized Fe-oxide NPs (nanohybrid or composite materials) from natural water even in the presence of interfering adsorption ions.

\section{2. $\mathrm{Pb}(\mathrm{II})$ Adsorption Experiments}

\subsection{1. $\mathrm{pH}$ and Adsorption Mechanism of $\mathrm{Pb}$ (II)}

As we already discussed for As, the adsorption performance of an adsorbent is strongly affected by many factors, such as the temperature, $\mathrm{pH}$, the type and size of the pores, the functional groups of the adsorbent surface, the type of adsorbate/adsorbent interaction, and, mainly, the nature of the adsorbate [106-113]. There are various mechanisms such as electrostatic attraction, host-host inclusion, chelation, etc., that are involved in the adsorption process $[30,114]$. For example, Nejad et al. [113] demonstrated that the $\mathrm{pH}$ is an important factor that cannot be overlooked in the heavy metal ion adsorbing process. The main reason is that it affects the surface charge of adsorbents, the ionization state of the adsorbates, binding sites of the Fe-oxide NPs, the degree of the surface area of ionization charge, the speciation of the adsorbate, and surface complexation [113-120]. Based on these factors, a proper $\mathrm{pH}$ value for the $\mathrm{Pb}$ ion adsorption process must be previously determined. 
Specifically, for a $\mathrm{pH}$ range of 2.0-6.0, $\mathrm{Pb}$ species exist exclusively as $\mathrm{Pb}(\mathrm{II})$ ions in the solution, being these the predominant adsorbing form of $\mathrm{Pb}$ (II). For a $\mathrm{pH}$ higher than $6.0, \mathrm{~Pb}$ ions undergo via hydrolysis to $\mathrm{Pb}(\mathrm{OH})^{+}$and $\mathrm{Pb}(\mathrm{OH})_{2}$ precipitates $[108,115,118]$, which are electrostatically unfavorable for the adsorption reaction $[113,114,117]$. Another factor that can strongly affect the $\mathrm{Pb}$ (II) uptake is the concentration of hydrogen $\left(\mathrm{H}^{+}\right)$or hydronium $\left(\mathrm{H}_{3} \mathrm{O}^{+}\right)$ions that increase their fractions with the decrease in the $\mathrm{pH}$. Consequently, it coexists in a competitive adsorption process that may occur between $\mathrm{H}^{+}$or $\mathrm{H}_{3} \mathrm{O}^{+}$ions and $\mathrm{Pb}$ (II). On increasing the $\mathrm{pH}$, the competitive effect of $\mathrm{H}_{3} \mathrm{O}^{+}$decreases, favoring the uptake process of $\mathrm{Pb}$ (II) ions on the free binding sites $[106,115]$. The p.z.c. of the adsorbent can reflect the influence of the $\mathrm{pH}$ on the adsorption process [116]. Thus, the measurements of $\mathrm{pH}_{\text {p.z.c. }}$ should also be considered for the $\mathrm{pH}$-sensitive adsorbent. The $\mathrm{pH}_{\text {p.z.c. }}$ is the value of $\mathrm{pH}$ in which the solution possesses equal numbers of positive and negative charges. On the one hand, at values below $\mathrm{pH}_{\text {p.z.c., }}$ the surface is positively charged, and the lower the $\mathrm{pH}$ is, the more positive is the surface charge of the adsorbent. In the last condition, the adsorption would be difficult due to the charge repulsion. On the other hand, at $\mathrm{pH}$ values higher than $\mathrm{pH}_{\text {p.z.c. }}$, the surface of the material is negatively charged, favoring, in this case, the adsorption of metal ions $[106,107,113,114,116]$. Nejad et al. [113] reported that for a $\mathrm{pH}_{\text {p.z.c. }}=8.8$, the highest adsorption capacity of the $\mathrm{Fe}_{3} \mathrm{O}_{4}-\mathrm{ETT}$ for $\mathrm{Pb}(\mathrm{II})$ was observed at $\mathrm{pH}$ 5.0. This result indicated that the $\mathrm{Fe}_{3} \mathrm{O}_{4}$-ETT surface is positively charged, suggesting that there is no electrostatic interaction between $\mathrm{Fe}_{3} \mathrm{O}_{4}$ - $\mathrm{ETT}$ and $\mathrm{Pb}$ (II). However, $\mathrm{Pb}$ (II) ions, as found in a Lewis acid, can interact with the $\pi$-electron pairs of the carbonyl functional group (Lewis's base) on the triazinetrione ring of $\mathrm{Fe}_{3} \mathrm{O}_{4}$-ETT [113]. In the same manner, the adsorption of the $\mathrm{Pb}(\mathrm{II})$ for $\mathrm{Fe}_{3} \mathrm{O}_{4} @-\mathrm{PEI} / \beta-\mathrm{CD}$ occurred to $\mathrm{pH}<\mathrm{pH}_{\text {p.z.c. }}$. Therefore, the adsorption capacities can be explained by the fact that the amino groups and oxygencontaining groups exhibit a strong chelating ability for $\mathrm{Pb}$ (II) ions [114]. However, the highest adsorption capacity for $\mathrm{Pb}$ (II) was found in $\mathrm{pH}=5.0$. This result indicates that the $\mathrm{Fe}_{3} \mathrm{O}_{4}$-ETT surface is positively charged, suggesting that there is no electrostatic interaction between $\mathrm{Fe}_{3} \mathrm{O}_{4}$-ETT and $\mathrm{Pb}$ (II). In particular, the nitrogen and oxygen-containing functional groups (with a strong chelating ability on the as-used adsorbent) played a crucial role in the complexing of $\mathrm{Pb}$ (II) [114]. A different adsorption mechanism is presented by Guo et al. [116], where the $\mathrm{pH}_{\text {p.z.c. }}$ of $\mathrm{Fe}_{3} \mathrm{O}_{4-\mathrm{g}}-\mathrm{C}_{3} \mathrm{~N}_{4}$ nanohybrids was found to be around 3.4, but an adsorption the capacity quickly improved with the $\mathrm{pH}$ increasing from 4 to 6 [116]. In this case, the adsorption was given by the electrostatic attractions, although the chemical interaction played a major role in adsorbing metal ions [116]. Figure 5 summarizes the main mechanisms of $\mathrm{Pb}$ (II) adsorption using Fe-oxide NPs.

Briefly, it could be inferred that the dependence of the adsorption capacity on the $\mathrm{pH}$ value can be strongly attributed to the change of the surface chemistry of the adsorbents with a $\mathrm{pH}$ modification. For example, if the surface of the adsorbents presents carboxyl groups at $\mathrm{pH}<\mathrm{pH}_{\text {p.z.c., }}$ the adsorption becomes low. As the $\mathrm{pH}$ increases, the carboxyl groups convert into anions carboxylate and adsorption gradually increase until $\mathrm{pH}>$ $\mathrm{pH}_{\text {p.z.c }}$. Hence, carboxyl groups completely turn into carboxylate anions with almost no change in the adsorption [118]. When the surface of the adsorbent presents hydroxyl groups (e.g., graphene) at a low $\mathrm{pH}$, the number of $\mathrm{H}^{+}$ions increases and the - $\mathrm{OH}$ groups become $-\mathrm{OH}_{2}^{+}$. This last chemical reaction leads to the adsorption capacity of $\mathrm{Pb}$ (II) ions on the surface of the adsorbent to decrease. At a high $\mathrm{pH}$, the -OH groups are ionized to $-\mathrm{O}^{-}$; thus, increasing the adsorption of $\mathrm{Pb}(\mathrm{II})$ ions [119]. Zhu et al. [110] reported the change of the $\zeta$-potential with the $\mathrm{pH}$ of $\mathrm{Fe}_{3} \mathrm{O}_{4} \mathrm{NPs}$, which is positive $(+28 \mathrm{mV})$ due to the formation of $+\mathrm{Fe}-\mathrm{OH}_{2}$ in a basic environment. However, when it is functionalized to obtain L-Cyst- $\mathrm{Fe}_{3} \mathrm{O}_{4} \mathrm{NPs}$, the composite has a negative zeta potential $(-30.2 \mathrm{mV})$. Therefore, it is worth mentioning that the L-cyst is negatively charged due to the carboxyl group present for $\mathrm{pH}<\mathrm{pH}_{\text {p.z.c. }}$ (5.1), but it is positively charged for $\mathrm{pH}>\mathrm{pH}_{\text {p.z.c. }}$ (5.1) due to the presence of the ammonium groups. Consequently, at $\mathrm{pH}=6.0$, $\mathrm{L}-\mathrm{Cyst}-\mathrm{Fe}_{3} \mathrm{O}_{4} \mathrm{NPs}$ have shown a negative zeta potential and an efficient $\mathrm{Pb}$ (II) removal [110]. 


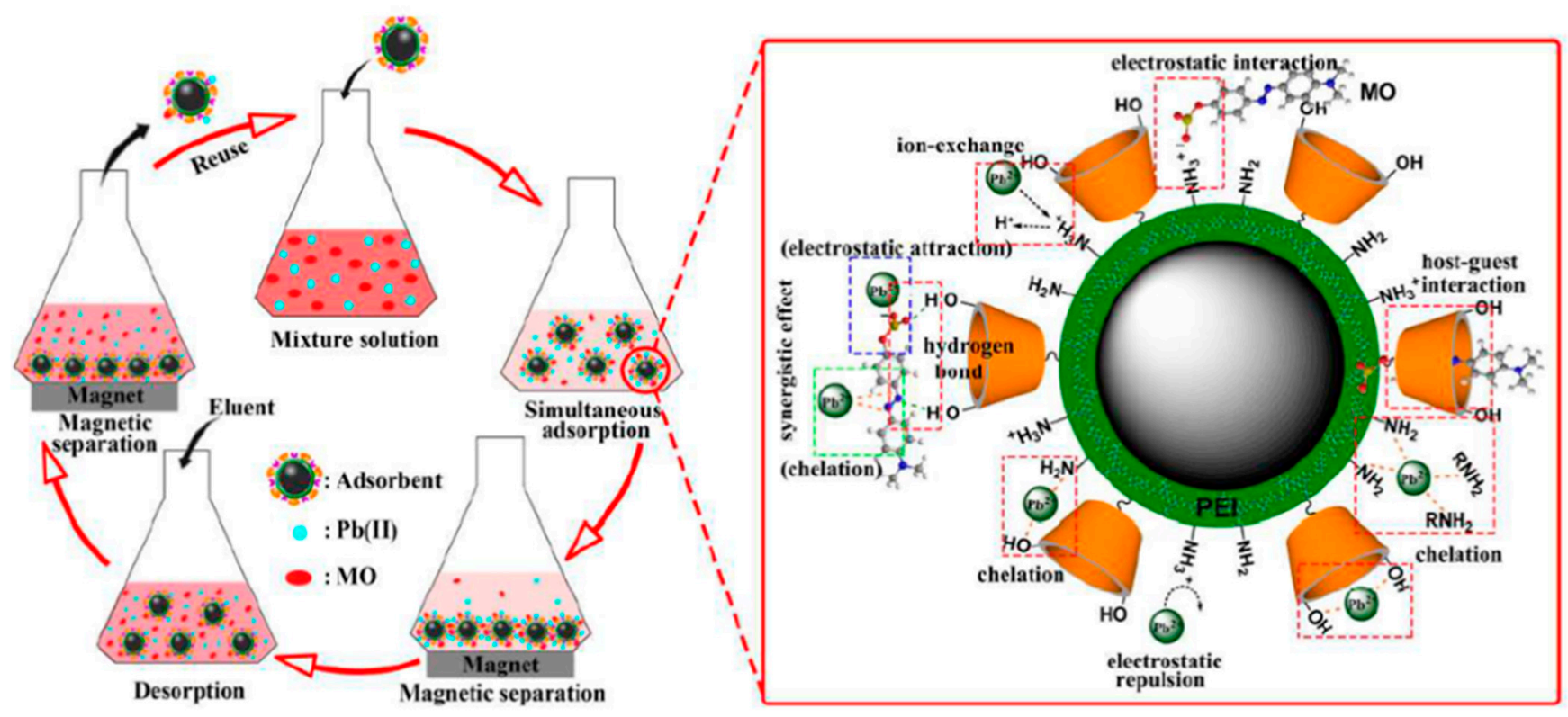

Figure 5. A versatile $\beta-C D$ and PEI bi-functionalized magnetic nanoadsorbent with spatially separated sorption sites (denoted as $\mathrm{Fe}_{3} \mathrm{O}_{4}$-PEI/ $\beta$-CD) was successfully constructed for simultaneous removal of methyl orange (MO) and $\mathrm{Pb}(\mathrm{II})$ from complex wastewater through multiple mechanisms (such as electrostatic attraction, host-guest inclusion, chelating, etc.); reproduced with permission of Elsevier [114].

Finally, the adsorption capacity of the adsorbent for metallic iron not only depends on the hydrolysis capacity of the metal ions and the competitive adsorption of coexisting materials in the aqueous solution, but it is also influenced by the chemical and physical properties of the adsorption. Thus, the adsorption capacity presents a gradually increasing trend when the $\mathrm{pH}$ value increases. This is attributed primarily to two main reasons: (i) the greater competition of metallic iron than $\mathrm{H}^{+}$for the combination of organic groups in acidic solutions which can cause an increase in adsorption, and (ii) the fact that metals have the tendency to hydrate to form $\mathrm{OH}^{-}$groups with $\mathrm{pH}$ increases. Thus, they present a more effective size and greater mobility [112,118].

\subsubsection{Effect of Initial Concentration on the Uptake of $\mathrm{Pb}(\mathrm{II})$}

Jia et al. [115] reported that a high initial concentration of $\mathrm{Pb}(\mathrm{II})$ ions provided a higher driving force between the solid-liquid interfaces to overcome resistance during the mass transfer process, resulting in a higher adsorption rate, until the initial concentration of $\mathrm{Pb}(\mathrm{II})$ ions reaches its equilibrium condition, which can also be affected in the presence of other divalent metals [121]. However, the percentage of $\mathrm{Pb}(\mathrm{II})$ removal decreases with increasing concentrations of $\mathrm{Pb}$ (II). This may be due to the occupation of available adsorption sites. In other words, they are fulfilled with high concentrations of $\mathrm{Pb}(\mathrm{II})$, preventing the capture of more ions $[30,114,121]$.

\subsubsection{Effect of Dosage on $\mathrm{Pb}(\mathrm{II})$ Removal}

An increase in the adsorbent dosage may result in the presence of excessive adsorption sites and the aggregation of the adsorbents in the solution. Therefore, causing a reduction in the effective available adsorption sites for the removal of $\mathrm{Pb}(\mathrm{II})$ and also in the adsorption capacity [115]. As an example, we took the $\mathrm{Fe}_{3} \mathrm{O}_{4}$-ETT hybrid that showed an improvement of the adsorption capacity when adsorbent doses increased from $1.0 \times 10^{-6}$ to $2.0 \times 10^{-5} \mathrm{~kg}$ for $\mathrm{Pb}(\mathrm{II})$, and then decreased gently on increasing adsorbent amounts. Nevertheless, the adsorption capacities after using $2.0 \times 10^{-5} \mathrm{~kg}$ decreased significantly. This results indicated that the active adsorption sites were effectively reduced for the $\mathrm{Pb}$ (II) adsorption with the subsequent increase in the $\mathrm{Fe}_{3} \mathrm{O}_{4}$-ETT dosage, showing the 
agglomeration of $\mathrm{Fe}_{3} \mathrm{O}_{4}$-ETT NPs [113]. Thus, it can be inferred that with the change of the adsorbent dose, there is a change in the removal efficiency percentage. The adsorption capacity for $\mathrm{Pb}$ (II) rises with an increasing ion concentration until reaching the maximum adsorption capacity [117]; compared to other adsorbents, they show a quick adsorption rate [118].

\subsubsection{Temperature Dependence of the $\mathrm{Pb}(\mathrm{II})$ Removal}

$\mathrm{Pb}$ (II) adsorption improves with an increasing temperature, suggesting that the process has an endothermic nature. Especially, it is assumed to be due to increased diffusion, the increased surface area of the adsorbent, and decreased viscosity of the solution. Therefore, by increasing the number of adsorption sites, due to the breaking of some internal bonds located on the edge of the particles, the adsorption of $\mathrm{Pb}$ (II) from the aqueous solution increases [106,119].

It was found that the uptake of $\mathrm{Pb}(\mathrm{II})$ by $\mathrm{Fe}_{3} \mathrm{O}_{4} @-\mathrm{PEI} / \beta-\mathrm{CD}$ was highly dependent on temperature and initial concentrations of adsorbates. High temperatures are more beneficial for the adsorption removal. For $\mathrm{Pb}$ (II) ions, the uptake amount increased gradually as initial concentration increased $[107,114]$. On the other hand, the results also suggested that when the temperature increased, the nanocomposites showed a tendency to lose weight that may be due to the elimination of residues [121]. Thus, it should be important to mention that thermal stability is another important factor that affects the direct application of an adsorbent. Therefore, under a high-temperature environment, the adsorbent must work properly, i.e., the composite degradation should be avoided. In general, it should be mentioned that nanocomposites have also shown a tendency to lose weight associated with ion removal [122]. A good example of composite material is the mHAP-oMWCNTs, which has a good thermal stability and achieves a mass balance at $600{ }^{\circ} \mathrm{C}$, where the mass loss is less than $14 \%$ up to $1000{ }^{\circ} \mathrm{C}$. The weight loss at high temperatures in this composite might have resulted from the removal of oxygen-containing groups [123].

\subsubsection{Simultaneous Removal of Divalent Metal Ions}

The competitive adsorption of coexisting ions to the binding sites is often a serious problem when using conventional adsorbents for heavy metal removal. However, the magnetic adsorbents not only have the hole as a mesopore structure with a large surface area and pore volume, but also their ferromagnetic features. These characteristics make them effective and convenient adsorbents for heavy metals removal if magnetic remediation is the main process [121].

Jia et al. [115] studied the adsorption of $\mathrm{Pb}$ (II) in the presence of coexisting $\mathrm{Cd}$ (II), $\mathrm{Ni}$ (II), $\mathrm{Cu}(\mathrm{II}), \mathrm{Pb}(\mathrm{II})$, and $\mathrm{Zn}$ (II) ions on $\mathrm{Fe}_{3} \mathrm{O}_{4} @ \mathrm{Si}_{2} @ \mathrm{PEI}-\mathrm{NTDA}$, resulting in a higher removal efficiency for $\mathrm{Pb}$ (II) than that for other metal ions. The competitive adsorption performance was given in the following order: $\mathrm{Pb}$ (II) $>\mathrm{Cd}$ (II) $>\mathrm{Zn}$ (II) $>\mathrm{Cu}$ (II) $>\mathrm{Ni}$ (II). According to Pearson's hard-soft acid-base theory, $\mathrm{Pb}(\mathrm{II})$ can be classified as a borderline acid and prefers bonding to ligands containing N-donor atoms. $\mathrm{Fe}_{3} \mathrm{O}_{4} @ \mathrm{Si}_{2} @ \mathrm{PEI}-\mathrm{NTDA}$, with a large number of $\mathrm{N}$ atoms in the polymer resin, may coordinate to $\mathrm{Pb}$ (II) rather than to $\mathrm{Cd}(\mathrm{II})$, which is classified as a soft acid. This behavior was also observed using $\mathrm{Fe}_{3} \mathrm{O}_{4}-\mathrm{FeMoS}_{4}-\mathrm{MgAl}-\mathrm{LDH}$, which stemmed from the soft Lewis base nature of sulfide $\mathrm{MoS}_{4}^{2+}$ ions [121]. They observed that the heavy metal ions acted as the soft Lewis acid and could be rapidly recovered, and selectivity captured from the aqueous solutions. The heavy metal ions adsorbed followed the sequence of $\mathrm{Pb}(\mathrm{II})>\mathrm{Cd}$ (II) $>\mathrm{Cu}$ (II) [121].

\subsubsection{Simultaneous $\mathrm{Pb}(\mathrm{II})$ and Organic Pollutants Adsorption}

Organic dyes and heavy metals had been widely found to coexist in groundwater or wastewater [114]. The uptake amount of $\mathrm{Pb}(\mathrm{II})$ increases significantly with an increasing concentration of co-existing $\mathrm{MO}$. This synergetic effect could be since anionic MO adsorbed on the $\mathrm{Fe}_{3} \mathrm{O}_{4} @-\mathrm{PEI} / \beta-\mathrm{CD}$ surface would provide additional active sites (such as $\mathrm{N}$-containing groups and sulfate groups) for $\mathrm{Pb}$ (II) uptake. The cationic $\mathrm{Pb}$ (II) seems 
to interact with - $\mathrm{SO}^{3-}$ of $\mathrm{MO}$ via electrostatic attraction; thus, improving the adsorption amounts of $\mathrm{Pb}$ (II) [114]. Wang et al. [111] reported the adsorption of $\mathrm{Pb}$ (II) and methylene blue (MB) on mHAP-oMWCNTs. The authors considered that the adsorption of $\mathrm{Pb}$ (II) is given by the ion exchange effect of HAP due to the content of $\mathrm{Ca}$ (II). For MB, the ion exchange effect of HAP no longer worked well and, consequently, the adsorption process mostly depended on oxygenic functional groups $(-\mathrm{COOH},-\mathrm{OH})[123]$.

\subsubsection{Removal of $\mathrm{Pb}$ (II) and Organic Compounds}

From Table S3, it can be seen that the highest adsorption capacity of $285.3 \mathrm{mg} \mathrm{g}^{-1}$ was obtained for nano- $\mathrm{Fe}_{3} \mathrm{O}_{4} @ \mathrm{Si}_{2} @ \mathrm{PEI}-\mathrm{NTDA}$ [115]. It provides numerous amine and anhydride groups that improve the adsorption capacity of the adsorbent due to their chelating configuration. Thus, the nano- $\mathrm{Fe}_{3} \mathrm{O}_{4} @ \mathrm{SiO}_{2} @ \mathrm{PEI}-\mathrm{NTDA}$ nanohybrid joins the binding capability of amino groups and functionalized carboxyl groups in the outer PEINTDA layer, substantially enhancing the adsorption properties of nano- $\mathrm{Fe}_{3} \mathrm{O}_{4}$. On the other hand, the saturation magnetization $\left(M_{s}\right)$ value decreased drastically to $21.6 \mathrm{emu} \mathrm{g}{ }^{-1}$, but the material was still susceptible to applied magnetic fields. Regarding functionalized Fe-oxide NPs, we bring another good example of drastic magnetization reduction $\left(M_{S}\right.$ value of $3.9 \mathrm{emu} \mathrm{g}^{-1}$ ) that was found in an $\mathrm{Fe}_{3} \mathrm{O}_{4} @ \mathrm{C} @ \mathrm{TiO}_{2}$ nanotube composite (labeled as $3 \mathrm{FeCTi}$. This nanocomposite was tested to $\mathrm{Pb}$ (II) removal, reaching an adsorption of $92 \%$ even in the presence of organic contaminant Rhodamine B (RhB). In other words, the magnetic remediation process showed that the low $M_{s}$ of the $3 \mathrm{FeCTi}$ nanohybrid does not affect the adsorption capacity and the 3FeCTi nanohybrid can first adsorb $\mathrm{Pb}$ (II) efficiently and still be separated from the effluent using an external magnetic field. A complex matrix formed by carbon nanotubes and $\mathrm{TiO}_{2}$ can be considered as a good candidate to prepare adsorbent materials applied to $\mathrm{Pb}(\mathrm{II})$ removal.

\subsection{8. $\mathrm{Pb}$ (II) Isotherm Models}

Equilibrium isotherm models explain how metal ions are distributed in liquid/solid phases [107]. When the Freundlich model better fits the experimental data, it indicates that the surface of the nanocomposite is heterogeneous and the adsorption of $\mathrm{Pb}$ (II) occurs in multilayer adsorptions with more surface heterogeneity $[11,113]$. On the other hand, the Langmuir model is reasonable for a homogeneous adsorption process that takes place at the adsorbent surface, where there are no intermolecular interactions among the adsorbed molecules and all sites are identical and energetically equivalent for the adsorbate $[115,119]$. The heavy metal ions, captured by the adsorbent, mostly follow the pseudo-second order model $[117,118,121]$. The adsorption process is well described by this intraparticle diffusion model; thus, the rate of adsorption of heavy metals is mainly controlled by the diffusion rate within the material pores $[117,118,122]$.

\subsubsection{Simultaneous Adsorption in Real Waters with Transition Metal-like Ions}

The uptake of several divalent heavy metals, such as $\mathrm{Ni}(\mathrm{II}), \mathrm{Pb}(\mathrm{II}), \mathrm{Cu}$ (II), and $\mathrm{Ni}$ (II) from river water, was studied by Fato et al. [124] using mesoporous $\mathrm{Fe}_{3} \mathrm{O}_{4} \mathrm{NPs}$. The $\mathrm{pH}$ dependence of the divalent heavy metals was tested at $25^{\circ} \mathrm{C}$ using an initial concentration of $10 \mathrm{mg} \mathrm{L}^{-1}$. The removal performance of $100 \%$ was achieved for a $\mathrm{pH}$ higher than 6.0 (a reduction in the removal efficiency is achieved below that $\mathrm{pH}$ ). The adsorption mechanism was found to be electrostatic in nature. At around $\mathrm{pH}=4.0$, the zeta potential started to increase to $-30 \mathrm{mV}$ and fluctuated from -20 to $-30 \mathrm{mV}$. This explains the higher uptake of the Fe-oxide NPs, since these values are recommendable for highly stable nanocolloids. The simultaneous removal was also tested in river water. The removal efficiency percentage varied from $60 \%$ to $80 \%$ for the $\mathrm{Pb}(\mathrm{II}), \mathrm{Cd}(\mathrm{II})$, and $\mathrm{Cu}(\mathrm{II})$ heavy metals in an equilibrium time of $120 \mathrm{~min}$. In the case of $\mathrm{Ni}(\mathrm{II})$, a removal efficiency percentage of $40 \%$ was achieved for an equilibrium time of $160 \mathrm{~min}$. No 100\% removal efficiency was achieved for the simultaneous experiment, revealing the competitive adsorption behavior for the divalent heavy metal uptake. 


\subsection{Physicochemical Properties of $\mathrm{Nano}-\mathrm{Fe}_{3} \mathrm{O}_{4}$ and $\mathrm{Nano}-\gamma-\mathrm{Fe}_{2} \mathrm{O}_{3}$ Influencing As and Pb(II) Adsorption}

Up to here, we discussed the influence of testing different physicochemical parameters in the $\mathrm{As}$ and $\mathrm{Pb}(\mathrm{II})$ adsorption processes using several Fe-oxide nanoadsorbents, and we can affirm that both $\mathrm{Fe}_{3} \mathrm{O}_{4}$ and $\gamma-\mathrm{Fe}_{2} \mathrm{O}_{3}$ NPs are excellent candidates to achieve a high percentage removal even in magnetic nanoarchitectures with small saturation magnetization, because the surface coating with inorganic and organic agents modifies the zeta potential and p.z.c. of the adsorbent and dotes the surface of chemical groups that favor the chemisorption of the heavy metals as shown in Figure 5, in case of $\mathrm{Pb}(\mathrm{II})$ adsorption; also discussed in Sections 4.1.3 and 4.2.1. regarding the adsorption mechanisms. Moreover, in cases where nano- $\mathrm{Fe}_{3} \mathrm{O}_{4}$ and nano- $\gamma-\mathrm{Fe}_{2} \mathrm{O}_{3}$ were tested alone for heavy metal removal, an endothermic reaction took place as suggested by Liu et al. [22].

On the other hand, a Fourier-transform infrared (FTIR) spectroscopy analysis was carried out in order to analyze the physicochemical properties of the functional IR groups of $\mathrm{As}(\mathrm{III})$ and $\mathrm{As}(\mathrm{V})$ species adsorbed onto bare $\gamma-\mathrm{Fe}_{2} \mathrm{O}_{3} \mathrm{NPs}$, binary $\mathrm{NPTiO}_{2}$, and ternary $\mathrm{NPGOTiO}_{2}$ nanocomposites, and also to confirm the adsorption mechanisms and physicochemical properties of the Fe-oxide NPs. A multiple peak fit was determined, where each noticeable IR mode was represented by a Lorentzian peak as presented in Figures 6 and 7 . Furthermore, the center positions of the Lorentzian lines are shown in Table 3. The characteristic IR broad bands of the As-O vibration mode have been previously identified at $800-950 \mathrm{~cm}^{-1}$ for $\mathrm{As}(\mathrm{V})[125,126]$. In the case of As(III) adsorption, the As-O band shifted from its characteristic position (at 780-800 $\mathrm{cm}^{-1}$ ) to the same range of $\mathrm{As}(\mathrm{V})$. This is because of the $\mathrm{As}$ (III) reduction caused by $\gamma-\mathrm{Fe}_{2} \mathrm{O}_{3} \mathrm{NPs}$. Moreover, it seems that $\mathrm{TiO}_{2}$ contributed negatively to the shifting, since Pena et al. [125] mentioned that As-O groups weakened with $\mathrm{As}$ (III) adsorption onto $\mathrm{TiO}_{2} \mathrm{NPs}$.

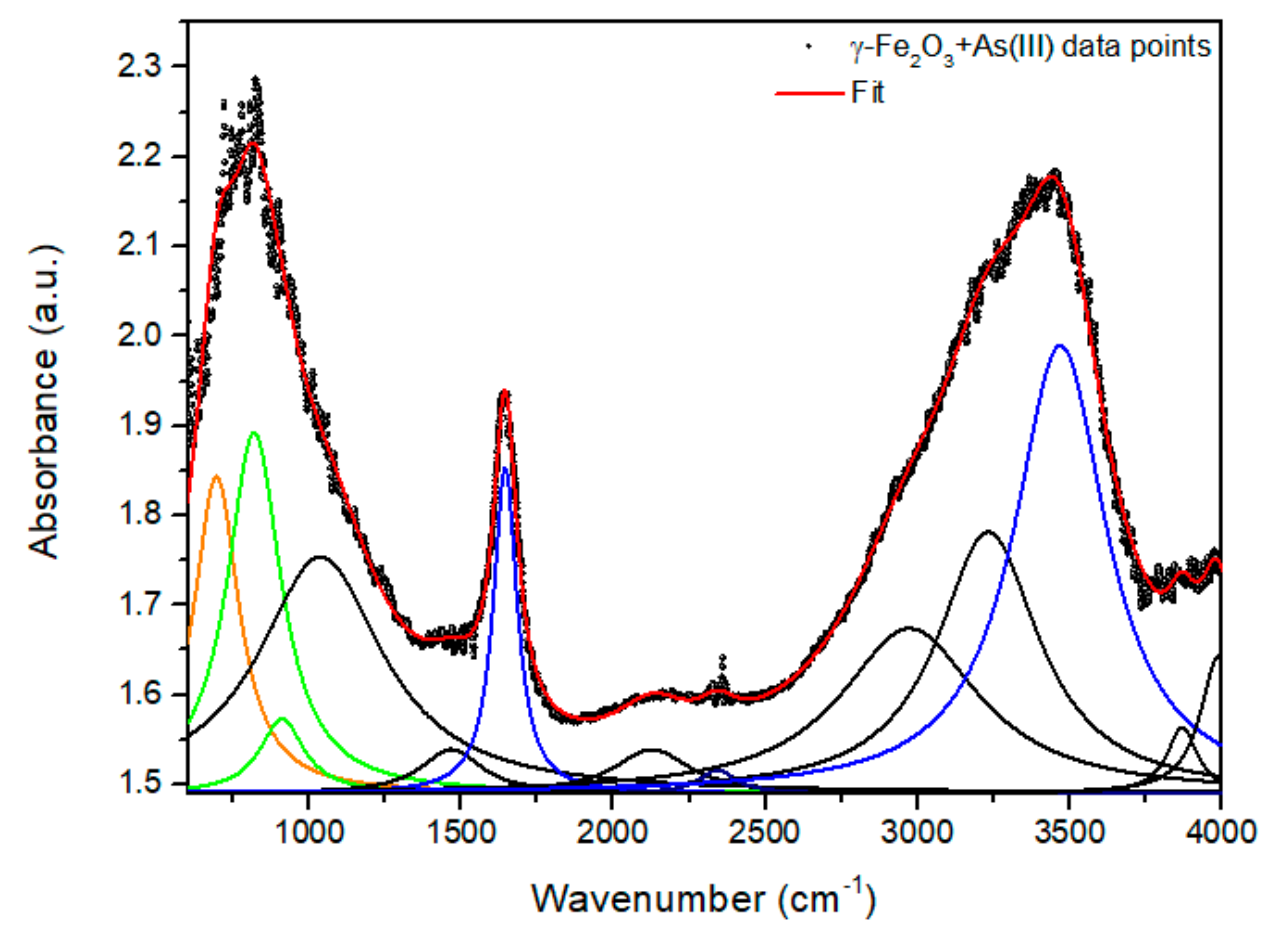

Figure 6. Fitted FTIR spectrum of the $\gamma-\mathrm{Fe}_{2} \mathrm{O}_{3} \mathrm{NPs}$ in $\mathrm{As}(\mathrm{III})$ solution. In the graph, the orange color indicates the Fe-O stretching mode, the green color to As-O, the blue color to $\mathrm{O}-\mathrm{H}$, and the black represents the background contribution. Figure developed by the authors. 

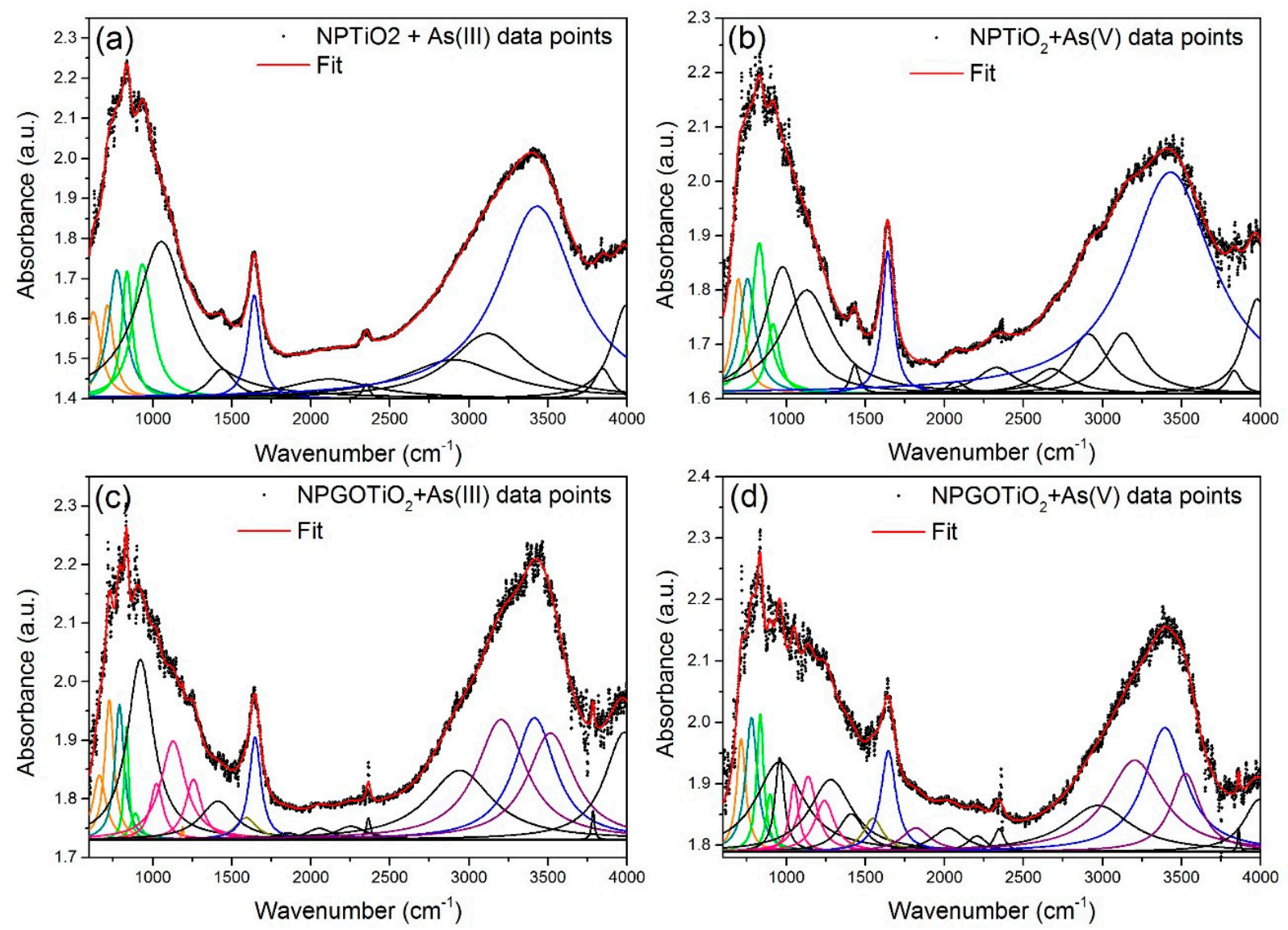

Figure 7. Fitted FTIR spectra of the $\mathrm{NPTiO}_{2}$ in (a) As (III) and (b) As (V) solutions, and $\mathrm{NPGOTiO}_{2}$ in (c) As(III) and (d) $\mathrm{As}(\mathrm{V})$ solutions. In the graphs, the orange color indicates the Fe-O stretching mode, the dark cyan is due to Ti-O, the green color to As-O, the pink color to $\mathrm{C}-\mathrm{O}$, the dark yellow to $\mathrm{C}=\mathrm{C}$, the blue color to $\mathrm{O}-\mathrm{H}$, the purple color to $\mathrm{C}-\mathrm{OH}$ and $\mathrm{COOH}$ groups, and the black represents the background contribution. Figure developed by the authors.

Table 3. Position centers of main modes of vibration. This table was developed from data of the IR spectra shown in Figures 6 and 7 .

\begin{tabular}{|c|c|c|c|c|c|}
\hline $\begin{array}{c}\text { Samples and Chemical } \\
\text { Groups }\end{array}$ & $\gamma-\mathrm{Fe}_{2} \mathrm{O}_{3}+\mathrm{As}$ (III) & $\mathrm{NPTiO}_{2}+$ As (III) & $\begin{array}{l}\mathrm{NPTiO}_{2}+\mathrm{As} \\
\text { (V) }\end{array}$ & $\begin{array}{l}\mathrm{NPGOTiO}_{2}+ \\
\text { As (III) }\end{array}$ & $\begin{array}{l}\mathrm{NPGOTiO}_{2}+ \\
\text { As (V) }\end{array}$ \\
\hline $\mathrm{Fe}-\mathrm{O}$ & 694 & 624.7 & 697 & 662.7 & 714 \\
\hline Ti-O & - & 773 & 754 & 789 & 779 \\
\hline As-O & 818.9 & 837.9 & 828.9 & 834 & 834.9 \\
\hline C-O (alcoxy) & - & - & - & 1024 & 1048 \\
\hline C-O (epoxy) & - & - & - & 1129 & 1137 \\
\hline C-O (carboxy) & - & - & - & 1257 & 1240 \\
\hline $\mathrm{C}=\mathrm{C}$ & - & - & - & 1591 & 1548 \\
\hline \multirow{3}{*}{$\mathrm{O}-\mathrm{O}-\mathrm{H}$} & 1644 & 1641 & 1641 & 1647 & 1645 \\
\hline & 3469 & 3431 & 3430 & 3414 & 3395 \\
\hline & - & - & - & 3205 & 3204 \\
\hline
\end{tabular}

According to Guivar et al. [42,43], $\gamma-\mathrm{Fe}_{2} \mathrm{O}_{3}$ characteristic absorption bands are located at $650-700 \mathrm{~cm}^{-1}$. In contrast to this, in Table 3 , absorption bands are more slightly dispersed. This could be attributed to nano- $\gamma-\mathrm{Fe}_{2} \mathrm{O}_{3}$ tetrahedral sites [127] that interact with $\mathrm{TiO}_{2} \mathrm{NPs}$ and As species. Additionally, it must be mentioned that nano- $\gamma-\mathrm{Fe}_{2} \mathrm{O}_{3}$ can present remaining peaks at $800-900 \mathrm{~cm}^{-1}[128,129]$, so part of the residual in this range in Figures 6 and 7 could be due to these infrared (IR) absorption bands. 
From these results, it can be inferred that the water functional group $\mathrm{O}-\mathrm{H}$ is present in all samples, as a wide peak centered at $3300-3500 \mathrm{~cm}^{-1}$ (stretching vibration) and a thin peak ca. $1640 \mathrm{~cm}^{-1}$ (bending vibration). However, in the presence of graphene oxide, this peak overlaps due to the stretching vibration band of the $\mathrm{C}=\mathrm{C}$ group (see Figure $7 \mathrm{c}, \mathrm{d}$ ) [42]. In presence of GO (see Figure 7c,d), carboxyl groups (C-O), alkoxy, epoxy, and carboxy have been identified at $1000-1300 \mathrm{~cm}^{-1}$ [42].

Despite several investigations being reported for the adsorption and removal of As species by using several magnetic nanohybrids, only few information has been found in the literature regarding the after-adsorption properties, especially explaining the surface mechanism for As removal. For example, Liu et al. [22] studied the As adsorption on $\mathrm{Fe}_{3} \mathrm{O}_{4} \mathrm{NPs}$ from water; and Dutta et al. [21] proposed a surface complexation in a hollow polyanine microsphere $/ \mathrm{Fe}_{3} \mathrm{O}_{4}$ nanocomposite. In both works [21,22], the As removal was explained based on the redox reaction and As-Fe complex via the ligand exchange mechanism. On the other hand, in a previous work, we were able to show that all studied samples were composed by pure $\gamma-\mathrm{Fe}_{2} \mathrm{O}_{3}$ NPs, as demonstrated by Mössbauer spectroscopy studies at $12 \mathrm{~K}$ [42]. Thus, the redox reaction mechanism, as suggested by Liu et al. [22], could not be expected because the core-shell configuration of $\mathrm{Fe}_{3} \mathrm{O}_{4} / \gamma-\mathrm{Fe}_{2} \mathrm{O}_{3} \mathrm{NPs}$ is a requirement and a competitive adsorption behavior between $\mathrm{Fe}(\mathrm{II})$ and $\mathrm{Fe}(\mathrm{III})$ species is not favored in pure nano- $\gamma-\mathrm{Fe}_{2} \mathrm{O}_{3}$ samples. Here, it is important to point out that the adsorption applications must be carried out immediately after sample preparation in case of the co-precipitation method (this to have a redox reaction mechanism) since the surface will react quickly and the $\mathrm{Fe}_{3} \mathrm{O}_{4} / \gamma-\mathrm{Fe}_{2} \mathrm{O}_{3}$ core-shell configuration will be time dependent for sizes smaller than $10 \mathrm{~nm}$ as we discussed in this review and, hence, significantly affecting the As or $\mathrm{Pb}$ (II) adsorption processes.

Another interesting scientific report is that from Mikutta et al. [130], who investigated the ternary complex formation between arsenate and ferric iron complexes conjugated with HA by means of X-ray absorption spectroscopy. They found that $70 \%$ of As coordinated with $\mathrm{Fe}(\mathrm{III})-\mathrm{HA}$ via an inner sphere complexation, forming a monodentate binuclear and monodentate mononuclear complex. It was also proposed that a complexation with Fe(III) behaves as an electron acceptor that increases the reduction in $\mathrm{As}(\mathrm{V})$; however, in the case of trivalent nano- $\gamma-\mathrm{Fe}_{2} \mathrm{O}_{3}$ samples, future studies are needed.

\subsection{Regeneration and Reuse of Magnetic Nanoadsorbents}

Once the Fe-oxide NPs show a high removal efficiency for heavy metals even in the presence of interferents and are applied in real water bodies, their regeneration and reuse must be studied to prove their sustainability. With the increase in synthesis and production of Fe-oxide NPs over the last 30 years, their release to the environment is inevitable and cycle regeneration must be carried out to control their liberation and reuse for diverse applications. Some works have reported the regeneration of magnetic NPs, for example, that of Shakeri et al. [131], who reported the regeneration protocol for the $\mathrm{Fe}_{3} \mathrm{O}_{4}$-based melamine-rich covalent organic polymer used for the removal of Auramine $\mathrm{O}(\mathrm{AO})$ and Rhodamine B (RB). The ethanol extraction technique was performed on the Fe-oxide NPs under nine cycles and the removal efficiency was $95 \%$ for $\mathrm{AO}$ and $88 \%$ for RB, suggesting the potential removal character of the Fe-oxide NPs. In another work, Behbahani et al. [121] tested the regeneration of $\mathrm{Fe}_{3} \mathrm{O}_{4} / \mathrm{FeMoS}_{4} / \mathrm{MgAl}-\mathrm{LDH}$ using (i) $20 \mathrm{~mL}$ of $0.1 \mathrm{~mol} \mathrm{~L}{ }^{-1} \mathrm{HCl}$ to achieve a surface heavy metal desorption, (ii) washing with distilled water three times (final $\mathrm{pH}$ of 6.0) and, finally, (iii) drying at $60{ }^{\circ} \mathrm{C}$ for the next use. After six cycles, the removal percentage was reduced by $5.1 \%$ for $\mathrm{Pb}(\mathrm{II}), 6.7 \%$ for $\mathrm{Cd}$ (II), and $8.5 \%$ for $\mathrm{Cu}(\mathrm{II})$ heavy metals. Xue et al. [132] studied the regeneration cycles for $\mathrm{Fe}_{3} \mathrm{O}_{4} \mathrm{NPs}$ modified with $\mathrm{HA}$, using $0.1 \mathrm{~mol} \mathrm{~L}^{-1} \mathrm{HCl}$ as the regenerative agent. After four desorption cycles, the adsorbent showed 95\% of removal efficiency for $\mathrm{Pb}(\mathrm{II}), \mathrm{Cu}(\mathrm{II}), \mathrm{Cd}(\mathrm{II})$, and of around $70 \%$ for $\mathrm{Ni}(\mathrm{II})$ in a high acidic medium of $\mathrm{pH}=1$.0. In addition, Ramos-Guivar et al. [133], using zeolite-type 5A functionalized $\gamma-\mathrm{Fe}_{2} \mathrm{O}_{3}$ NPs, demonstrated that a removal efficiency of $82 \%$ was achieved after seven regeneration cycles for $0.1 \mathrm{~mol} \mathrm{~L}^{-1} \mathrm{HCl}, 70 \mathrm{mg} \mathrm{L}^{-1} \mathrm{~Pb}(\mathrm{II})$, 
and $\mathrm{pH}=5.5$. Despite all the previous magnetic nanoadsorbents depicting high removal efficiency after regeneration, the use of $\mathrm{HCl}$ at the pilot and industrial levels is still an open theme. Moreover, the physicochemical composition of the adsorbents needs to be deeply studied to corroborate the permanence of the structural and magnetic properties.

\subsection{Cost Evaluation}

There are few literatures that discuss the cost/prices and industrial-level implementation of these nanoadsorbents focusing on the water magnetic remediation method. A good example is given by Baig et al. [134], who discussed the prices of granulated nanoadsorbents. These authors suggested that the cost/price may vary between 1 and $5.14 \mathrm{USD} / \mathrm{g}$ of As removed for six different adsorbents, including Fe-oxide-coated sorbents, granular ferric hydroxide, iron ore, and zero valence iron. However, considering the case of functionalized Fe-oxide NPs (functionalization with inorganic and organic agents), it drastically increases their production costs. For example, if Fe-oxide NPs are combined with multiwall carbon nanotubes, these nanohybrids will require several steps to activate their surfaces with carboxyl and hydroxyl groups, which often take several hours. Thus, the use of acidic activators that, at industrial levels, leads to the contamination and abuse of several liters of water. The same procedure is required for the chemical activation of GO, limiting its use for industrial applications. The combined nanohybrids of two, three, or even four phases will increase the removal efficiency but will also rise the cost of production. Hence, the nanomaterials used for water magnetic remediation must have a high purity, but without sacrificing the removal efficiency. By evaluating the performance of a pure nano- $\gamma-\mathrm{Fe}_{2} \mathrm{O}_{3}$ at laboratory conditions [42], a removal efficiency of $85 \%$ for $\mathrm{As}(\mathrm{III})$ and $\mathrm{As}(\mathrm{V})$ was achieved, and the cost evaluation, regarding chemical reactive, water amounts, and pre-evaluation laboratory adsorption, suggested prices of 3.68-5.18 USD/g As removed, assuming an initial concentration of $136 \mathrm{mg} \mathrm{L}^{-1}$, which is higher than the one reported in Southern America countries (concentrations of $50 \mu \mathrm{g} \mathrm{L}^{-1}$ ) [17]. However, the long quantities to be used of these nanoadsorbents (in terms of kilograms or tons) in real polluted water, at high industrial levels, have not been evaluated up to the moment; thus, this issue is still lacking.

Therefore, the major tested experiments were performed in batch adsorption in simulated polluted water (synthetic effluents), and no discussions have been conducted in the major literature about the scalability of the proposed nanohybrids; it becomes a challenge to have a cost evaluation of the potential nanoadsorbent in which the final price will not sacrifice the applicability because the employment of combined adsorbent will certainly increase the production cost, including variables such as reactive prices, the synthesis time and equipment, plant design, consuming energy, training personal, among others. A great approach has been recently proposed by Augusto et al. [135], where an upscale design was performed for nanomagnetic particle production. Definitely, in the upcoming years, the demand for the use of these nanoadsorbents will increase as the heavy metal pollution areas spread and their impacts will drastically affect the environment (even more than today). Thus, an urgent call to the mining companies and Environmental Sciences Ministers of all countries to invest in these kinds of nanotechnologies is necessary. In other words, it is also mandatory to have more rigorous control and protection laws of the water bodies conjugated with the development of new nanoadsorption hybrid materials to keep the human impact at an acceptable level.

\section{Conclusions}

Water remediation for cleaning heavy metal ions (e.g., As, $\mathrm{Pb}, \mathrm{Cd}$, etc.) by employing magnetic nanohybrids is a hot and emerging topic that still requires more investigation as suggested in this review that compiled some of the most relevant papers reported in the literature. Despite adsorption having been suggested as a fast and efficient method to treat polluted waters with $\mathrm{As}$ and $\mathrm{Pb}$ cations, the magnetic properties of magnetic Fe-oxide NPs should be well understood to facilitate the entire removal procedure, i.e., magnetic structures of nanohybrids need to be comprehended because these nanoadsorbents should 
be magnetically manipulated using an applied field either in bare or with functionalized surface adsorption properties. Two of the most common Fe-oxide NPs suggested to be used in the magnetic remediation process are nanomagnetite and nanomaghemite, but they have different magnetic and catalytic properties and, therefore, still need further investigation. However, by proving the efficient removal and nanotoxicity properties of Fe-oxide NPs, the next steps to be considered are the scale up process and industrial level applications, considering their impacts in the environment and the final cost. Therefore, improvements in the synthesis methods still need to be undertaken together with an in-detail characterization of course, before liberating big quantities of these nanoadsorbents in soil and aquatic environments. In the present review, it was first summarized that the chemical methods (strong emphasis in co-precipitation and thermal decomposition methods) often used to synthesize magnetic hybrid nanoadsorbents based on $\mathrm{Fe}_{3} \mathrm{O}_{4}$ and $\gamma-\mathrm{Fe}_{2} \mathrm{O}_{3}$ NPs and their main differences, as studied by many physicochemical techniques (X-ray diffraction, zero and in-field Mössbauer spectroscopy, XPS, and synchrotron radiation techniques). From a deeper characterization of Fe-oxide NPs, we have demonstrated that high resolution experimental techniques are necessary, and the in-field Mössbauer technique seems to be the most appropriate experimental method to differentiate between $\mathrm{Fe}_{3} \mathrm{O}_{4}$ and $\gamma-\mathrm{Fe}_{2} \mathrm{O}_{3}$ NPs with sizes smaller than $10 \mathrm{~nm}$. Using data from the literature, we also showed that the synthesized nano- $\mathrm{Fe}_{3} \mathrm{O}_{4}$ is sensitive to quick oxidation to nano- $\gamma-\mathrm{Fe}_{2} \mathrm{O}_{3}$ (entire particle or only its surface) that occurred a few hours immediately after the sample drying process. The partial oxidation effect can lead to a core-shell-like model $\left(\mathrm{Fe}_{3} \mathrm{O}_{4} / \gamma-\mathrm{Fe}_{2} \mathrm{O}_{3}\right)$, where competitive surface magnetic effects should be well understood. For instance, the surface spin effect causes a reduction in the $M_{s}$ to values of about $3.9 \mathrm{emu}^{-1}$ of the nanoadsorbents. In other words, for a further understanding of the adsorption mechanism that happens on $\mathrm{Fe}_{3} \mathrm{O}_{4}$ and $\gamma-\mathrm{Fe}_{2} \mathrm{O}_{3} \mathrm{NP}$ surfaces, high resolution spectroscopy techniques should be applied in order to bring information about magnetic properties and their catalytic properties during the divalent cation's removal process. In particular, the removal of $\mathrm{As}$ and $\mathrm{Pb}$ from contaminated synthetic effluent was discussed by focusing on different physicochemical parameters. Zeta potential must be a mandatory technique to study not only the Fe-oxide NPs colloidal stability, but also to calculate the p.z.c. of the adsorbent at different $\mathrm{pH}$ values, helping to figure out the adsorption mechanism. Moreover, the use of FTIR, XPS, in-field Mössbauer, and synchrotron radiation techniques (all together) will help to clarify the different adsorption and also functionalization mechanisms.

\section{Future Perspectives}

Regeneration and recycling properties suggest that the magnetic nanohybrids can be stored and reused for various adsorption-desorption tests. However, the protocols to desorb the heavy metals still require the use of acidic treatments and represent a future challenge in the field of magnetic nanoadsorbents. On the other hand, there is no reports bringing information on how to store and recover the heavy metal/acid complex. The magnetic nanohybrids can be used in environments with many coexisting anions, divalent metals, and organic compounds to simultaneously adsorb the heavy metals. However, there is also a lack in the literature regarding pilot and industrial applications of these functionalized (or not) Fe-oxide NPs, especially by mining companies that are still using conventional and long-period treatment cleaning procedures. Additionally, no cost evaluation has been available frequently in the literature. The major studies focused and competed for the better adsorbent (batch laboratory tests) by using binary and ternary nanoadsorbents that can compromise the price and scale up demands in upcoming years, mainly for countries in development that have aqueous environments polluted with coexisting heavy metals and other organic species. Finally, the after adsorption properties also need to be carried out to better understand the physicochemical properties of the non-functionalized and functionalized Fe-oxide NPs and their influences on the As and $\mathrm{Pb}$ (II) removal mechanism. This will help to identify the sustainability and storage of the magnetic properties and re-use of the magnetic NPs. 
Supplementary Materials: The following are available online at https:/ / www.mdpi.com/article/10 .3390/nano11092310/s1. Table S1: structure and adsorption parameters of magnetic nanohybrids used for $\mathrm{As}(\mathrm{III})$ and $\mathrm{As}(\mathrm{V})$ adsorption, Table S2: the adsorption parameters for removal of arsenic and other pollutants from water using diverse magnetic nanohybrids, Table S3: lead, other metals, and pollutant adsorption parameters for magnetic nanohybrids. A list of acronyms was also included.

Author Contributions: Conceptualization, J.A.R.-G. and D.A.F.-C.; methodology, J.A.R.-G.; software, J.A.R.-G. and D.A.F.-C.; validation, J.A.R.-G. and D.A.F.-C.; formal analysis, J.A.R.-G. and D.A.F.-C.; investigation, J.A.R.-G. and D.A.F.-C.; resources, J.A.R.-G.; data curation, J.A.R.-G. and D.A.F.-C.; writing-original draft preparation, J.A.R.-G., D.A.F.-C., and E.C.P.; writing-review and editing, J.A.R.-G., D.A.F.-C., and E.C.P.; visualization, J.A.R.-G., D.A.F.-C., and E.C.P.; supervision, J.A.R.-G.; project administration, J.A.R.-G.; funding acquisition, J.A.R.-G. All authors have read and agreed to the published version of the manuscript.

Funding: The authors thank the Fondo Nacional de Desarrollo Científico, Tecnológico y de Innovación Tecnológica (PROCIENCIA-CONCYTEC), project number: 177-2020-FONDECYT (PROCIENCIA), project CLEAN NANOMAGNETIC. The APC was funded by PROCIENCIA.

Data Availability Statement: The original data related to this research can be asked any time to the corresponding author's email: juan.ramos5@unmsm.edu.pe.

Acknowledgments: Edson C. Passamani is also thankful to FAPES and CNPq for their financial support in the infrastructure of Ufes's laboratory under his supervision. We finally thank Jean-Marc Greneche for supporting us with the in-field Mössbauer measurement of NPEDTA samples.

Conflicts of Interest: The authors declare no conflict of interest.

\section{References}

1. Cornell, R.M.; Schwertmann, U. The Iron Oxides: Structure, Properties, Reactions, Occurrences and Uses, 2nd ed.; Wiley-VCH Verlag GmbH \& Co. KGaA: Weinheim, Württemberg, Germany, 2003.

2. Oh, S.J.; Cook, D.C.; Townsend, H.E. Characterization of iron oxides commonly formed as corrosion products on steel. Hyperfine Interact. 1998, 112, 59-66. [CrossRef]

3. Nedkov, I.; Merodiiska, T.; Slavov, L.; Vandenberghe, R.E.; Kusano, Y.; Takada, J. Surface Oxidation, size, and shape of nano-sized magnetite obtained by co-precipitation. J. Magn. Magn. Mater. 2006, 300, 358-467. [CrossRef]

4. Sun, X.; Huls, N.F.; Sigdel, A.; Sun, S. Tuning Exchange Bias in Core/Shell FeO/ $\mathrm{Fe}_{3} \mathrm{O}_{4}$ nanoparticles. Nano Lett. 2012 , 12 , $246-251$. [CrossRef]

5. De Carvalho, J.F.; De Medeiros, S.N.; Morales, M.A.; Dantas, A.L.; Carriço, A.S. Synthesis of magnetite nanoparticles by high energy ball milling. Appl. Surf. Sci. 2013, 275, 84-87. [CrossRef]

6. Roth, H.-C.; Schwaminger, S.P.; Schindler, M.; Wagner, F.E.; Berensmeier, S. Influencing factors in the CO-precipitation process of superparamagnetic iron oxide nanoparticles: A model-based study. J. Magn. Magn. Mater. 2015, 377, 81-89. [CrossRef]

7. Hah, H.Y.; Gray, S.; Johnson, C.E.; Johnson, J.A.; Kolesnichenko, V.; Kucheryavy, P.; Goloverda, G. Mössbauer spectroscopy of superparamagnetic $\mathrm{Fe}_{3} \mathrm{O}_{4}$ nanoparticles. J. Magn. Magn. Mater. 2021, 539, 168382. [CrossRef]

8. Lavorato, G.C.; Rubert, A.A.; Xing, Y.; Das, R.; Robles, J.; Litterst, F.J.; Baggio-Saitovitch, E.; Phan, M.-H.; Srikanth, H.; Vericat, C.; et al. Shell-mediated control of surface chemistry of highly stoichiometric nanomagnetite nanoparticles. Nanoscale 2020, 12, 13626-13636. [CrossRef] [PubMed]

9. $\quad$ Bhattacharjee, S.; Mazumder, N.; Mondal, S.; Panigrahi, K.; Banerjee, A.; Das, D.; Sarkar, S.; Roy, D.; Chattopadhyay, K.K. Size-modulation of functionalized $\mathrm{Fe}_{3} \mathrm{O}_{4}$ : Nanoscopic customization to devise resolute piezoelectric nanocomposites. Dalton Trans. 2020, 49, 7872-7890. [CrossRef] [PubMed]

10. Hwang, Y.; Angappane, S.; Park, J.; An, K.; Hyeon, T.; Park, J.G. Exchange bias behavior of monodisperse $\mathrm{Fe}_{3} \mathrm{O}_{4} / \gamma-\mathrm{Fe}_{2} \mathrm{O}_{3}$ core/shell nanoparticles. Curr. Appl. Phys. 2012, 12, 808-811. [CrossRef]

11. Perez, G.; Romero, M.P.; Saitovitch, E.B.; Litterst, F.J.; Araujo, J.F.D.F.; Bell, D.C.; Solorzano, G. Alkali concentration effects on the composition, morphology, and magnetic properties of magnetite, maghemite and iron oxyhydroxide nanoparticles. Solid State Sci. 2020, 106, 106295. [CrossRef]

12. Da Costa, G.M.; Blanco-Andujar, C.; De Grave, E.; Pankhurst, Q.A. Magnetic Nanoparticles for in vivo use: A critical assessment of their composition. J. Phys. Chem. B 2014, 118, 11738-11746. [CrossRef]

13. Tuček, J.; Zboril, R.; Petridis, D. Maghemite nanoparticles by view of Mössbauer spectroscopy. J. Nanosci. Nanotechnol. 2006, 6, 926-947. [CrossRef] [PubMed]

14. Greneche, J.-M. The contribution of ${ }^{57} \mathrm{Fe}$ Mossbauer spectrometry to investigate magnetic nanomaterials. In Mössbauer Spectrocopy, 1st ed.; Yoshida, Y., Langouche, G., Eds.; Springer: Berlin/Heidelberg, Germany, 2013.

15. Lata, S.; Samadder, S.R. Removal of arsenic from water using nanoadsorbents and challenges: A review. J. Environ. Manag. 2016, 166, 387-406. [CrossRef] 
16. Hao, L.; Liu, M.; Wang, N.; Li, G. A critical review on arsenic removal from water using iron-based adsorbents. RSC Adv. 2018, 8, 39545-39560. [CrossRef]

17. Bundschuh, J.; Schneider, J.; Alam, M.A.; Niazi, N.K.; Herath, I.; Parvez, F.; Tomaszewska, B.; Guilherme, L.R.G.; Maity, J.P.; López, D.L.; et al. Seven potential sources of arsenic pollution in Latin America and their environmental and health impacts. Sci. Total Environ. 2021, 780, 146274. [CrossRef]

18. Habuda-Stanić, M.; Nujić, M. Arsenic removal by nanoparticles: A review. Environ. Sci. Pollut. Res. 2015, 22, 8094-8123. [CrossRef]

19. World Health Organization (WHO). Arsenic, Fact Sheet No 372; WHO: Geneva, Switzerland, 2012.

20. Bissen, M.; Frimmel, F.H. Arsenic-A review. Part II: Oxidation of arsenic and its removal in water treatment. Acta Hydrochim. Hydrobiol. 2003, 31, 97-107. [CrossRef]

21. Dutta, S.; Manna, K.; Srivastava, S.K.; Gupta, A.K.; Yadav, M.K. Hollow polyalinine microsphere $/ \mathrm{Fe}_{3} \mathrm{O}_{4}$ nanocomposite as an effective adsorbent for removal of arsenic from water. Sci. Rep. 2020, 10, 4982. [CrossRef] [PubMed]

22. Liu, C.-H.; Chuang, Y.-H.; Chen, T.-Y.; Tian, Y.; Li, H.; Wang, M.-K.; Zhang, W. Mechanism of arsenic adsorption on magnetite nanoparticles from water: Thermodynamic and spectroscopic studies. Environ. Sci. Technol. 2015, 49, 7726-7734. [CrossRef] [PubMed]

23. Massart, R. Preparation of aqueous magnetic liquids in alkaline and acidic media. IEEE Trans. Magn. 1981, 17, 1247-1248. [CrossRef]

24. Jolivet, J.P.; Froidefond, C.; Pottier, A.; Chanéac, C.; Cassaignon, S.; Tronc, E.; Euzenb, P. Size tailoring of oxide nanoparticles by precipitation in aqueous medium. A semi-quantitative modelling. J. Mater. Chem. 2004, 14, 3281-3288. [CrossRef]

25. Goya, G.F.; Grazú, V.; Ibarra, M.R. Magnetic nanoparticles for cancer therapy. Curr. Nanosci. 2008, 4, 1-16. [CrossRef]

26. Randrianantoandro, N.; Mercier, A.M.; Hervieu, M.; Grenèche, J.M. Direct phase transformation from hematite to maghemite during high energy ball milling. Mater. Lett. 2001, 47, 150-158. [CrossRef]

27. Lux, H. Iron (II) hydroxide. In Handbook of Preparative Inorganic Chemistry, 2nd ed.; Brauer, G., Ed.; Academic Press: New York, NY, USA, 1965; Volume 2, pp. 1498-1499.

28. Jolivet, J.P.; Chanéac, C.; Prené, P.; Vayssières, L.; Tronc, E. Wet Chemistry of Spinel Iron oxide Particles. J. Phys. IV 1997, 7, C1-573-C1-576. [CrossRef]

29. Gokon, N.; Shimada, A.; Haneko, H.; Tamura, Y.; Ito, K.; Ohara, T. Magnetic coagulation and reaction rate for the aqueous ferrite formation reaction. J. Magn. Magn. Mater. 2002, 238, 47-55. [CrossRef]

30. Ramos-Guivar, J.A.; López, E.O.; Greneche, J.-M.; Litterst, F.J.; Passamani, E.C. Effect of EDTA organic coating on the spin canting behavior of maghemite nanoparticles for lead (II) adsorption. Appl. Surf. Sci. 2021, 538, 148021. [CrossRef]

31. Ramos Guivar, J.A.; Passamani, E.C.; Litterst, F.J. Superspinglass state in functionalized zeolite 5A-maghemite nanoparticles. AIP Adv. 2021, 11, 035223. [CrossRef]

32. Liu, S.; Yu, B.; Wang, S.; Shen, Y.; Cong, H. Preparation, surface functionalization and application of $\mathrm{Fe}_{3} \mathrm{O}_{4}$ magnetic nanoparticles. Adv. Colloid Interface Sci. 2020, 281, 102-165. [CrossRef]

33. Sun, S.; Zeng, H. Size-Controlled Synthesis of Magnetite Nanoparticles. J. Am. Chem. Soc. 2002, 124, 8204-8205. [CrossRef] [PubMed]

34. Ortiz-Godoy, N.; Agredo-Diaz, D.G.; Garzón-Posada, A.O.; Parra Vargas, C.A.; Landínez Téllez, D.A.; Roa-Rojas, J. A facile method to produce magnetic nanoparticles and its influence on their magnetic and physical properties. Mater. Lett. 2021, 293, 129700. [CrossRef]

35. Gorski, C.A.; Scherer, M.M. Determination of nanoparticulate magnetite stoichiometry by Mössbauer spectroscopy, acidic dissolution, and powder X-ray diffraction: A critical review. Am. Mineral. 2010, 95, 1017-1026. [CrossRef]

36. Tronc, E.; Fiorani, D.; Noguès, M.; Testa, A.M.; Lucari, F.; D’Orazio, F.; Greneche, J.M.; Wernsdorfer, W.; Gálvez, N.; Chanéac, C.; et al. Surface effects in noninteracting and interacting $\gamma-\mathrm{Fe}_{2} \mathrm{O}_{3}$ nanoparticles. J. Magn. Magn. Mater. 2003, 262, 6-14. [CrossRef]

37. Mørup, S.; Topsøe, H. Mossbauer studies of thermal excitations in magnetically ordered microcrystals. Appl. Phys. 1976, 11, 63-66. [CrossRef]

38. Mørup, S.; Hansen, B.R. Uniform magnetic excitations in nanoparticles. Phys. Rev. B 2005, 72, 024418. [CrossRef]

39. Millan, A.; Urtizberea, A.; Silva, N.J.O.; Palacio, F.; Amaral, V.S.; Snoeck, E.; Serin, V. Surface effects in maghemite nanoparticles. J. Magn. Magn. Mater. 2007, 312, L5-L9. [CrossRef]

40. Shokrollahi, H. A review of the magnetic properties, synthesis methods and applications of maghemite. J. Magn. Magn. Mater. 2017, 426, 74-81. [CrossRef]

41. Guivar, J.A.R.; Sanches, E.A.; Bruns, F.; Sadrollahi, E.; Morales, M.A.; López, E.O.; Litterst, F.J. Vacancy ordered $\gamma$-Fe ${ }_{2} \mathrm{O}_{3}$ nanoparticles functionalized with nanohydroxyapatite: XRD, FTIR, XPS and Mossbauer studies. Appl. Surf. Sci. 2016, 389, 721-734. [CrossRef]

42. Guivar, J.A.R.; Bustamante, A.G.; Gonzalez, J.C.; Sanches, E.A.; Morales, M.A.; Raez, J.M.; López-Muñoz, M.J.; Arencibia, A. Adsorption of arsenite and arsenate by binary and ternary magnetic nanocomposites with high iron oxide content. Appl. Surf. Sci. 2018, 454, 87-100. [CrossRef]

43. Guivar, J.A.R.; Sadrollahi, E.D.; Menzel, D.; Ramos Fernandes, E.G.; López, E.O.; Torres, M.M.; Arsuaga, J.M.; Arencibia, A.; Litterst, F.J. Magnetic, structural and surface properties of functionalized maghemite nanoparticles for copper and lead adsorption. RSC Adv. 2017, 7, 28763-28779. [CrossRef] 
44. Torasso, N.; Vergara-Rubio, A.; Rivas-Rojas, P.; Huck-Iriart, C.; Larrañaga, A.; Fernández-Cirelli, A.; Cerveny, S.; Goyanes, S. Enhancing arsenic adsorption via excellent dispersion of iron oxide nanoparticles inside poly(vinyl alcohol) nanofibers. J. Environ. Chem. Eng. 2020, 9, 104664. [CrossRef]

45. Frison, R.; Cernuto, G.; Cervellino, A.; Zaharko, O.; Colonna, G.M.; Guagliardi, A.; Masciocchi, N. Magnetite-Maghemite Nanoparticles in the 5-15 nm Range: Correlating the Core-Shell Composition and the Surface Structure to the Magnetic Properties. A Total Scattering Study. Chem. Mater. 2013, 25, 4820-4827. [CrossRef]

46. Di Lorio, E.; Colombo, C.; Cheng, Z.; Capitani, G.; Mele, D.; Ventruti, G.; Angelico, R. Characterization of magnetite nanoparticles synthetized from $\mathrm{Fe}(\mathrm{II}) /$ nitrate solutions for arsenic removal from water. J. Environ. Chem. Eng. 2019, 7, 102986. [CrossRef]

47. Yu, X.; Tong, S.; Ge, M.; Zuo, J.; Cao, C.; Song, W. One-step synthesis of magnetic composites of cellulose@iron oxide nanoparticles for arsenic removal. J. Mater. Chem. A 2013, 1, 959-965. [CrossRef]

48. Menard, M.C.; Marschilok, A.C.; Takeuchi, K.J.; Takeuchi, E.S. Variation in the iron oxidation states of magnetite nanocrystals as a function of crystallite size: The impact on electrochemical capacity. Electrochim. Acta 2013, 94, 320-326. [CrossRef]

49. Ngoi, K.H.; Wong, J.C.; Chiu, W.S.; Chia, C.H.; Jin, K.S.; Kim, H.-J.; Kim, H.-C.; Ree, M. Morphological structure details, size distributions and magnetic properties of iron oxide nanoparticles. J. Ind. Eng. Chem. 2021, 95, 37-50. [CrossRef]

50. Daou, T.J.; Greneche, J.-M.; Lee, S.-J.; Lee, S.; Lefevre, C.; Bégin-Colin, S.; Pourroy, G. Spin canting of maghemite studied by NMR and in-field Mössbauer spectrometry. J. Phys. Chem. C 2010, 114, 8794-8799. [CrossRef]

51. Schwaminger, S.P.; Syhr, C.; Berensmeier, S. Controlled Synthesis of Magnetic Iron Oxide Nanoparticles: Magnetite or Maghemite? Crystals 2020, 10, 214. [CrossRef]

52. González-Alonso, D.; Espeso, J.I.; Gavilán, H.; Zeng, L.; Díaz, M.T.F.; Subías, G.; de Pedro, I.; Fernández, J.R.; Bender, P.; Barquín, L.F.; et al. Identifying the presence of magnetite in an ensemble of iron-oxide nanoparticles: A comparative neutron diffraction study between bulk and nanoscale. Nanoscale Adv. 2021, 3, 3491-3496. [CrossRef]

53. Iyengar, S.J.; Joy, M.; Ghosh, C.K.; Dey, S.; Kotnala, R.K.; Ghosh, S. Magnetic, X-ray and Mossbauer studies on magnetite/maghemite core-shell nanostructures fabricated through an aqueous route. RSC. Adv. 2014, 4, 64919-64929. [CrossRef]

54. Dormann, J.L.; D’Orazio, F.; Lucari, F.; Tronc, E.; Prené, P.; Jolivet, J.P.; Fiorani, D.; Cherkaoui, R.; Noguès, M. Thermal variation of the relaxation time of the magnetic moment of $\gamma-\mathrm{Fe}_{2} \mathrm{O}_{3}$ nanoparticles with interparticle interaction of various strengths. Phys. Rev. B 1996, 53, 14291-14297. [CrossRef]

55. Wilson, D.; Langell, M.A. XPS analysis of oleylamine/oleic acid capped $\mathrm{Fe}_{3} \mathrm{O}_{4}$ nanoparticles as a function of temperature. Appl. Surf. Sci. 2014, 303, 6-13. [CrossRef]

56. Jiménez-Villacorta, F.; Prieto, C.; Huttel, Y.; Telling, N.D.; Van Der Laan, G. X-ray magnetic circular dichroism study of the blocking process in nanostructured iron-iron oxide core-shell systems. Phys. Rev. B 2011, 84, 172404. [CrossRef]

57. Bonanni, V.; Basini, M.; Peddis, D.; Lascialfari, A.; Rossi, G.; Torelli, P. X-ray magnetic circular dichroism discloses surface spins correlation in maghemite hollow nanoparticles. Appl. Phys. Lett. 2018, 112, 022404. [CrossRef]

58. Siddiqui, S.I.; Singh, P.N.; Tara, N.; Pal, S.; Chaudhry, S.A.; Sinha, I. Arsenic removal from water by starch functionalized maghemite nano-adsorbents: Thermodynamics and kinetics investigations. Colloids Interface Sci. Commun. 2020, $36,100263$. [CrossRef]

59. Navarathna, C.M.; Karunanyake, A.G.; Gunatilake, S.R.; Pittman, C.U., Jr.; Perez, F.; Mohan, D.; Mlsna, T.E. Removal of Arsenic(III) from water using magnetite precipitated onto Douglas fir biochar. J. Environ. Manag. 2019, 250, 109429. [CrossRef]

60. Pizarro, C.; Escudey, M.; Caroca, E.; Pavez, C.; Zúñiga, G.E. Evaluation of zeolite, nanomagnetite and nanomagnetite-zeolite composite materials as arsenic (V) adsorbents in hydroponic tomato cultures. Sci. Total Environ. 2021, 751, 141623. [CrossRef]

61. Hernández-Flores, H.; Pariona, N.; Herrera-Trejo, M.; Hdz-García, H.M.; Mtz-Enriquez, A.I. Concrete/maghemite nanocomposites as novel adsorbents for arsenic removal. J. Mol. Struct. 2018, 1171, 9-16. [CrossRef]

62. Das, T.K.; Sakthivel, T.S.; Jeyaranjan, A.; Seal, S.; Bezbaruah, A.N. Ultra-high arsenic adsorption by graphene oxide iron nanohybrid: Removal mechanisms and potential applications. Chemosphere 2020, 253, 126702. [CrossRef]

63. Raval, N.P.; Kumar, M. Geogenic arsenic removal through core-shell based functionalized nanoparticles: Groundwater in-situ treatment perspective in the post-COVID anthropocene. J. Hazard. Mater. 2021, 402, 123466. [CrossRef]

64. Su, H.; Ye, Z.; Hmidi, N. High-performance iron oxide-graphene oxide nanocomposite adsorbents for arsenic removal. Colloids Surf. A Physicochem. Eng. Asp. 2017, 522, 161-172. [CrossRef]

65. Zeng, H.; Zhai, L.; Qiao, T.; Yu, Y.; Zhang, J.; Li, D. Efficient removal of As(V) from aqueous media by magnetic nanoparticles prepared with Iron-containing water treatment residuals. Sci. Rep. 2020, 10, 9335. [CrossRef] [PubMed]

66. Das, T.K.; Bezbaruah, A.N. Comparative study of arsenic removal by iron-based nanomaterials: Potential candidates for field applications. Sci. Total Environ. 2021, 10, 142914. [CrossRef] [PubMed]

67. Leus, K.; Folens, K.; Nicomel, N.R.; Perez, J.P.H.; Filippousi, M.; Meledina, M.; Dîrtu, M.M.; Turner, S.; Van Tendeloo, G.; Garcia, Y.; et al. Removal of arsenic and mercury species from water by covalent triazine framework encapsulated $\gamma-\mathrm{Fe}_{2} \mathrm{O}_{3}$ nanoparticles. J. Hazard. Mater. 2018, 353, 312-319. [CrossRef] [PubMed]

68. Siddiqui, S.I.; Chaudhry, S.A. Nanohybrid composite $\mathrm{Fe}_{2} \mathrm{O}_{3}-\mathrm{ZrO}_{2} / \mathrm{BC}$ for inhibiting the growth of bacteria and adsorptive removal of arsenic and dyes from water. J. Clean. Prod. 2019, 223, 849-868. [CrossRef]

69. Alchouron, J.; Navarathna, C.; Chludil, H.D.; Dewage, N.B.; Perez, F.; Hassan, E.B.; Pittman, C.U., Jr.; Vega, A.S.; Mlsna, T.E. Assessing South American Guadua chacoensis bamboo biochar and $\mathrm{Fe}_{3} \mathrm{O}_{4}$ nanoparticle dispersed analogues for aqueous arsenic(V) remediation. Sci. Total Environ. 2020, 706, 135943. [CrossRef] 
70. Maziarz, P.; Matusik, J.; Leiviskä, T.; Strączek, T.; Kapusta, C.; Woch, W.M.; Tokarz, W.; Górniak, K. Toward highly effective and easily separable halloysite-containing adsorbents: The effect of iron oxide particles impregnation and new insight into As(V) removal mechanisms. Sep. Purif. Technol. 2019, 210, 390-401. [CrossRef]

71. Ajith, N.; Swain, K.K. Study on the performance and interaction of different synthetic iron oxides for arsenic uptake using ${ }^{76}$ As radiotracer. Appl. Radiat. Isot. 2019, 153, 108807. [CrossRef]

72. Alchouron, J.; Navarathna, C.; Rodrigo, P.M.; Snyder, A.; Chludil, H.D.; Vega, A.S.; Bosi, G.; Perez, F.; Mohan, D.; Pittman, C.U., Jr.; et al. Household arsenic contaminated water treatment employing iron oxide/ bamboo biochar composite: An approach to technology transfer. J. Colloid Interface Sci. 2021, 587, 767-779. [CrossRef]

73. Nisticò, R.; Celi, L.R.; Prevot, A.B.; Carlos, L.; Magnacca, G.; Zanzo, E.; Martin, M. Sustainable magnet-responsive nanomaterials for the removal of arsenic from contaminated water. J. Hazard. Mater. 2018, 342, 260-269. [CrossRef] [PubMed]

74. Nikić, J.; Tubić, A.; Watson, M.; Maletić, S.; Šolić, M.; Majkić, T.; Agbaba, J. Arsenic Removal from Water by Green Synthesized Magnetic Nanoparticles. Water 2019, 11, 2520. [CrossRef]

75. Liu, J.; Kong, L.; Huang, X.; Liu, M.; Li, L. Removal of arsenic(V) from aqueous solutions using sulfur-doped $\mathrm{Fe}_{3} \mathrm{O}_{4}$ nanoparticles. RSC. Adv. 2018, 8, 40804-40812. [CrossRef]

76. Zeng, H.; Zhai, L.; Qiao, T.; Zhang, J.; Li, D. Removal of As(V) by a core-shell magnetic nanoparticles synthesized with iron-containing water treatment residuals. Colloids Surf. A Physicochem. Eng. Asp. 2021, 627, 127074. [CrossRef]

77. Zeng, H.; Zhai, L.; Zhang, J.; Li, D. As(V) adsorption by a novel core-shell magnetic nanoparticles prepared with Iron-containing water treatment residuals. Sci. Total Environ. 2021, 753, 142002. [CrossRef]

78. Feng, L.; Cao, M.; Ma, X.; Zhu, Y.; Hu, C. Superparamagnetic high-surface-area $\mathrm{Fe}_{3} \mathrm{O}_{4}$ nanoparticles as adsorbents for arsenic removal. J. Hazard. Mater. 2012, 217-218, 439-446. [CrossRef] [PubMed]

79. Wu, K.; Jing, C.; Zhang, J.; Liu, T.; Yang, S.; Wang, W. Magnetic $\mathrm{Fe}_{3} \mathrm{O}_{4} @ \mathrm{CuO}$ nanocomposite assembled on graphene oxide sheets for the enhanced removal of arsenic(III/V) from water. Appl. Surf. Sci. 2019, 466, 746-756. [CrossRef]

80. An, B.; Liang, Q.; Zhao, D. Removal of arsenic(V) from spent ion exchange brine using a new class of starch-bridged magnetite nanoparticles. Water Res. 2011, 45, 1961-1972. [CrossRef] [PubMed]

81. Tuutijärvi, T.; Lu, J.; Sillanpää, M.; Chen, G. As(V) adsorption on maghemite nanoparticles. J. Hazard. Mater. 2009, 166, 1415-1420. [CrossRef] [PubMed]

82. Song, K.; Kim, W.; Suh, C.Y.; Shin, D.; Ko, K.S.; Ha, K. Magnetic iron oxide nanoparticles prepared by electrical wire explosion for arsenic removal. Powder Technol. 2013, 246, 572-574. [CrossRef]

83. Lin, Y.F.; Chen, J.L. Synthesis of mesoporous maghemite $\left(\gamma-\mathrm{Fe}_{2} \mathrm{O}_{3}\right)$ nanostructures with enhanced arsenic removal efficiency. RSC Adv. 2013, 3, 15344-15349. [CrossRef]

84. Cui, J.; Jin, Q.; Li, Y.; Li, F. The oxidation and removal of As(III) from soil using a novel magnetic nanocomposite derived-biomass wastes. Environ. Sci. Nano 2019, 6, 478-488. [CrossRef]

85. He, R.; Peng, Z.; Lyu, H.; Huang, H.; Nan, Q.; Tang, J. Synthesis and characterization of an iron-impregnated biochar for aqueous arsenic removal. Sci. Total Environ. 2018, 612, 1177-1186. [CrossRef]

86. Deng, M.; Wu, X.; Zhu, A.; Zhang, Q.; Liu, Q. Well-dispersed $\mathrm{TiO}_{2}$ nanoparticles anchored on $\mathrm{Fe}_{3} \mathrm{O}_{4}$ magnetic nanosheets for efficient arsenic removal. J. Environ. Manag. 2019, 237, 63-74. [CrossRef] [PubMed]

87. Lin, Y.F.; Chen, J.L.; Xu, C.Y.; Chung, T.W. One-pot synthesis of paramagnetic iron(III) hydroxide nanoplates and ferrimagnetic magnetite nanoparticles for the removal of arsenic ions. Chem. Eng. Sci. 2014, 250, 409-415. [CrossRef]

88. Akin, I.; Arslan, G.; Tor, A.; Ersoz, M.; Cengeloglu, Y. Arsenic(V) removal from underground water by magnetic nanoparticles synthesized from waste red mud. J. Hazard. Mater. 2012, 235-236, 62-68. [CrossRef]

89. Siddiqui, S.I.; Naushad, M.; Chaudhry, S.A. Promising prospects of nanomaterials for arsenic water remediation: A comprehensive review. Process Saf. Environ. Prot. 2019, 126, 60-97. [CrossRef]

90. Narouei, F.H.; Andreescu, D.; Andreescu, S. Rapid characterization of arsenic adsorption on single magnetite nanoparticles by collisions at microelectrodes. Environ. Sci. Nano 2020, 7, 1999-2009. [CrossRef]

91. Paul, B.; Parashar, V.; Mishra, A. Graphene in the $\mathrm{Fe}_{3} \mathrm{O}_{4}$ nano-composite switching the negative influence of humic acid coating into an enhancing effect in the removal of arsenic from water. Environ. Sci. Water Res. Technol. 2015, 1, 77-83. [CrossRef]

92. Rashid, M.; Sterbinsky, G.E.; Gracia Pinilla, M.A.; Cai, Y.; O’Shea, K.E. Kinetic and Mechanistic Evaluation of Inorganic Arsenic Species Adsorption onto Humic Acid Grafted Magnetite Nanoparticles. J. Phys. Chem. C 2018, 122, 13540-13547. [CrossRef]

93. Taleb, K.; Markovski, J.; Veličković, Z.; Rusmirović, J.; Rančić, M.; Pavlović, V.; Marinković, A. Arsenic removal by magnetiteloaded amino modified nano/microcellulose adsorbents: Effect of functionalization and media size. Arab. J. Chem. 2019, 12, 4675-4693. [CrossRef]

94. Darezereshki, E.; Khodadadi Darban, A.; Abdollahy, M.; Jamshidi-Zanjani, A. Influence of heavy metals on the adsorption of arsenate by magnetite nanoparticles: Kinetics and thermodynamic. Environ. Nanotechnol. Monit. Manag. 2018, 10, 51-62. [CrossRef]

95. Lung, I.; Stan, M.; Opris, O.; Soran, M.L.; Senila, M.; Stefan, M. Removal of lead(II), cadmium(II), and arsenic(III) from aqueous solution using magnetite nanoparticles prepared by green synthesis with Box-Behnken design. Anal. Lett. 2018, 51, $2517-2531$. [CrossRef]

96. Yoon, Y.; Zheng, M.; Ahn, Y.T.; Park, W.K.; Yang, W.S.; Kang, J.W. Synthesis of magnetite/non-oxidative graphene composites and their application for arsenic removal. Sep. Purif. Technol. 2017, 178, 40-48. [CrossRef] 
97. Kango, S.; Kumar, R. Magnetite nanoparticles coated sand for arsenic removal from drinking water. Environ. Earth Sci. 2016, 75, 381. [CrossRef]

98. Tripathy, M.; Hota, G. Maghemite and graphene oxide embedded polyacrylonitrile electrospun nanofiber matrix for remediation of arsenate ions. ACS Appl. Polym. Mater. 2020, 2, 604-617. [CrossRef]

99. Chiew, H.; Sampson, M.L.; Huch, S.; Ken, S.; Bostick, B.C. Effect of Groundwater Iron and Phosphate on the Efficacy of Arsenic Removal by Iron-Amended BioSand Filters. Environ. Sci. Technol. 2009, 43, 6295-6300. [CrossRef]

100. Markovski, J.S.; Dokić, V.; Milosavljević, M.; Mitrić, M.; Perić-Grujić, A.A.; Onjia, A.E.; Marinković, A.D. Ultrasonic assisted arsenate adsorption on solvothermally synthesized calcite modified by goethite, $\alpha-\mathrm{MnO}_{2}$ and goethite $/ \alpha-\mathrm{MnO}_{2}$. Ultrason . Sonochem. 2014, 21, 790-801. [CrossRef]

101. Markovski, J.S.; Marković, D.D.; Dokić, V.R.; Mitrić, M.; Ristić, M.D.; Onjia, A.E.; Marinković, A.D. Arsenate adsorption on waste eggshell modified by goethite, $\alpha-\mathrm{MnO}_{2}$ and goethite $/ \alpha-\mathrm{MnO}_{2}$. Chem. Eng. J. 2014, 237, 430-442. [CrossRef]

102. Issa, N.B.; Rajaković-Ognjanović, V.N.; Marinković, A.D.; Rajaković, L.V. Separation and determination of arsenic species in water by selective exchange and hybrid resins. Anal. Chim. Acta 2011, 706, 191-198. [CrossRef]

103. Tombácz, E.; Tóth, I.Y.; Nesztor, D.; Illés, E.; Hajdú, A.; Szekeres, M.; Vékás, L. Adsorption of organic acids on magnetite nanoparticles, pH-dependent colloidal stability and salt tolerance. Colloids Surf. A Physicochem. Eng. Asp. 2013, 435, 91-96. [CrossRef]

104. Foo, K.Y.; Hameed, B.H. Insights into the modeling of adsorption isotherm systems. Chem. Eng. J. 2010, 156, 2-10. [CrossRef]

105. Goldberg, S.; Johnston, C.T. Mechanisms of arsenic adsorption on amorphous oxides evaluated using macroscopic measurements, vibrational spectroscopy, and surface complexation modeling. J. Colloid Interface Sci. 2001, 234, 204-216. [CrossRef]

106. Bagbi, Y.; Sarswat, A.; Mohan, D.; Pandey, A.; Solanki, P.R. Lead $\left(\mathrm{Pb}^{2+}\right)$ adsorption by monodispersed magnetite nanoparticles: Surface analysis and effects of solution chemistry. J. Environ. Chem. Eng. 2016, 4, 4237-4247. [CrossRef]

107. Rajput, S.; Pittman, C.U., Jr.; Mohan, D. Synthesis of Magnetic Magnetite Nanoparticles $\left(\mathrm{Fe}_{3} \mathrm{O}_{4}\right)$ and applications for lead removal $\left(\mathrm{Pb}^{2+}\right)$ and chromium $\left(\mathrm{Cr}^{6+}\right)$ of the water. J. Colloid Interface Sci. 2015, 468, 334-346. [CrossRef] [PubMed]

108. Verma, R.; Asthana, A.; Singh, A.K.; Prasad, S.; Susan, M.A.B.H. Novel glycine-functionalized magnetic nanoparticles entrapped calcium alginate beads for effective removal of lead. Microchem. J. 2017, 130, 168-178. [CrossRef]

109. Bagbi, Y.; Sarswat, A.; Mohan, D.; Pandey, A.; Solanki, P.R. Lead and chromium adsorption from water using L-cysteine functionalized magnetite $\left(\mathrm{Fe}_{3} \mathrm{O}_{4}\right)$ nanoparticles. Sci. Rep. 2017, 7, 7672. [CrossRef] [PubMed]

110. Zhu, H.; Tan, X.; Tan, L.; Zhang, H.; Liu, H.; Fang, M.; Hayat, T.; Wang, X. Magnetic porous polymers prepared through high internal phase emulsions for efficient removal of $\mathrm{Pb}^{2+}$ and $\mathrm{Cd}^{2+}$. ACS Sustain. Chem. Eng. 2018, 6, 5206-5213. [CrossRef]

111. Wang, N.; Yang, D.; Wang, X.; Yu, S.; Wang, H.; Wen, T.; Song, G.; Yu, Z.; Wang, X. Highly efficient removal of Pb(II) and Cu(II) using hollow $\mathrm{Fe}_{3} \mathrm{O}_{4} @ P D A$ nanoparticles with excellent applicability and reusability. Inorg. Chem. Front. 2018, 5, $2174-2182$. [CrossRef]

112. Hosseinzadeh, M.; Seyyed Ebrahimi, S.A.; Raygan, S.; Masoudpanah, S.M. Removal of cadmium and lead ions from aqueous solution by nanocrystalline magnetite through mechanochemical activation. J. Ultrafine Grained Nanostruct. Mater. 2016, 49, 72-79.

113. Nejad, S.B.; Mohammadi, A. Epoxy-triazinetrione-functionalized magnetic nanoparticles as an efficient magnetic nanoadsorbent for the removal of malachite green and $\mathrm{Pb}$ (II) from aqueous solutions. J. Chem. Eng. Data 2020, 65, 2731-2742. [CrossRef]

114. Chen, B.; Chen, S.; Zhao, H.; Liu, Y.; Long, F.; Pan, X. A versatile $\beta$-cyclodextrin and polyethyleneimine bi-functionalized magnetic nanoadsorbent for simultaneous capture of methyl orange and $\mathrm{Pb}$ (II) from complex wastewater. Chemosphere 2019, 216, 605-616. [CrossRef]

115. Jia, C.; Zhao, J.; Lei, L.; Kang, X.; Lu, R.; Chen, C.; Li, S.; Zhao, Y.; Yang, Q.; Chen, Z. Novel magnetically separable anhydridefunctionalized $\mathrm{Fe}_{3} \mathrm{O}_{4} @ \mathrm{SiO}_{2} @$ PEI-NTDA nanoparticles as effective adsorbents: Synthesis, stability and recyclable adsorption performance for heavy metal ions. RSC Adv. 2019, 9, 9533-9545. [CrossRef]

116. Guo, S.; Wu, K.; Gao, Y.; Liu, L.; Zhu, X.; Li, X.; Zhang, F. Efficient Removal of Zn(II), Pb(II), and Cd(II) in Waste Water Based on Magnetic Graphitic Carbon Nitride Materials with Enhanced Adsorption Capacity. J. Chem. Eng. Data 2018, 63, 3902-3912. [CrossRef]

117. Chen, K.; He, J.; Li, Y.; Cai, X.; Zhang, K.; Liu, T.; Hu, Y.; Lin, D.; Kong, L.; Liu, J. Removal of cadmium and lead ions from water by sulfonated magnetic nanoparticle adsorbents. J. Colloid Interface Sci. 2017, 494, 307-316. [CrossRef]

118. Ge, F.; Li, M.; Ye, H.; Zhao, B. Effective removal of heavy metal ions $\mathrm{Cd}^{2+}, \mathrm{Zn}^{2+}, \mathrm{Pb}^{2+}, \mathrm{Cu}^{2+}$ from aqueous solution by polymermodified magnetic nanoparticles. J. Hazard. Mater. 2012, 211-212, 366-372. [CrossRef]

119. Zhang, C.; Sui, J.; Li, J.; Tang, Y.; Cai, W. Efficient removal of heavy metal ions by thiol-functionalized superparamagnetic carbon nanotubes. Chem. Eng. J. 2012, 210, 45-52. [CrossRef]

120. Bi, J.; Huang, X.; Wang, J.; Wang, T.; Wu, H.; Yang, J.; Lu, H.; Hao, H. Oil-phase cyclic magnetic adsorption to synthesize $\mathrm{Fe}_{3} \mathrm{O}_{4} @ \mathrm{C} @ \mathrm{TiO}_{2}$-nanotube composites for simultaneous removal of $\mathrm{Pb}(\mathrm{II})$ and rhodamine B. Chem. Eng. J. 2019, 366, 50-61. [CrossRef]

121. Behbahani, E.S.; Dashtian, K.; Ghaedi, M. $\mathrm{Fe}_{3} \mathrm{O}_{4}-\mathrm{FeMoS}_{4}$ : Promise magnetite LDH-based adsorbent for simultaneous removal of $\mathrm{Pb}(\mathrm{II}), \mathrm{Cd}(\mathrm{II})$, and $\mathrm{Cu}(\mathrm{II})$ heavy metal ions. J. Hazard. Mater. 2021, 410, 124560. [CrossRef]

122. Li, G.; Zhao, Z.; Liu, J.; Jiang, G. 2011. Effective heavy metal removal from aqueous systems by thiol functionalized magnetic mesoporous silica. J. Hazard. Mater. 2011, 192, 277-283. 
123. Wang, Y.; Hu, L.; Zhang, G.; Yan, T.; Yan, L.; Wei, Q.; Du, B. Removal of Pb(II) and methylene blue from aqueous solution by magnetic hydroxyapatite-immobilized oxidized multi-walled carbon nanotubes. J. Colloid Interface Sci. 2017, 494, 380-388. [CrossRef] [PubMed]

124. Fato, F.P.; Li, D.W.; Zhao, L.J.; Qiu, K.; Long, Y.T. Simultaneous removal of multiple heavy metal ions from river water using ultrafine mesoporous magnetite nanoparticles. ACS Omega 2019, 4, 7543-7549. [CrossRef]

125. Pena, M.; Meng, X.; Korfiatis, G.P.; Jing, C. Adsorption mechanism of arsenic on nanocrystalline titanium dioxide. Environ. Sci. Technol. 2006, 40, 1257-1262. [CrossRef]

126. Carabante, I.; Grahn, M.; Holmgren, A.; Kumpiene, J.; Hedlund, J. Adsorption of As (V) on iron oxide nanoparticle films studied by in situ ATR-FTIR spectroscopy. Colloids Surf. A Physicochem. Eng. Asp. 2009, 346, 106-113. [CrossRef]

127. Ogholbeyg, A.B.; Kianvash, A.; Hajalilou, A.; Abouzari-Lotf, E.; Zarebkohan, A. Cytotoxicity characteristics of green assistedsynthesized superparamagnetic maghemite $\left(\gamma-\mathrm{Fe}_{2} \mathrm{O}_{3}\right)$ nanoparticles. J. Mater. Sci. Mater. Electron. 2018, 29, 12135-12143. [CrossRef]

128. Hui, B.H.; Salimi, M.N. Production of iron oxide nanoparticles by co-precipitation method with optimization studies of processing temperature, $\mathrm{pH}$ and stirring rate. In IOP Conference Series: Materials Science and Engineering; IOP Publishing: Bristol, UK, 2020; Volume 743, p. 012036.

129. Nazari, M.; Ghasemi, N.; Maddah, H.; Motlagh, M.M. Synthesis and characterization of maghemite nanopowders by chemical precipitation method. J. Nanostruct. Chem. 2014, 4, 99. [CrossRef]

130. Mikutta, C.; Kretzschmar, R. Spectroscopic evidence for ternary complex formation between arsenate and ferric iron complexes of humic substances. Environ. Sci. Technol. 2011, 45, 9550-9557. [CrossRef] [PubMed]

131. Shakeri, S.; Rafiee, Z.; Dashtian, $\mathrm{K}$. $\mathrm{Fe}_{3} \mathrm{O}_{4}$-based melamine-rich covalent organic polymer for simultaneous removal of auramine O and rhodamine B. J. Chem. Eng. Data 2020, 65, 696-705. [CrossRef]

132. Xue, S.; Xiao, Y.; Wang, G.; Fan, J.; Wan, K.; He, Q.; Gao, M.; Miao, Z. Adsorption of heavy metals in water by modifying $\mathrm{Fe}_{3} \mathrm{O}_{4}$ nanoparticles with oxidized humic acid. Colloids Surf. A Physicochem. Eng. Asp. 2021, 616, 126333. [CrossRef]

133. Ramos-Guivar, J.A.; Taipe, K.; Schettino, M.A., Jr.; Silva, E.; Morales Torres, M.A.; Passamani, E.C.; Litterst, F.J. Improved removal capacity and equilibrium time of maghemite nanoparticles growth in zeolite type $5 \mathrm{~A}$ for $\mathrm{Pb}(\mathrm{II})$ adsorption. Nanomaterials $\mathbf{2 0 2 0}$ 10, 1668. [CrossRef]

134. Baig, S.A.; Sheng, T.; Hu, Y.; Xu, J.; Xu, X. Arsenic removal from natural water using low-cost granulated adsorbents: A review. Clean Soil Air Water 2015, 43, 13-26. [CrossRef]

135. Augusto, P.A.; Castelo-Grande, T.; Vargas, D.; Pascual, A.; Hernández, L.; Estevez, A.M.; Barbosa, D. Upscale Design, Process Development, and Economic Analysis of Industrial Plants for Nanomagnetic Particle Production for Environmental and Biomedical Use. Materials 2020, 13, 2477. [CrossRef] 